\title{
Response of the Atlantic overturning circulation to South Atlantic sources of buoyancy
}

\author{
Wilbert Weijer and Wilhelmus P. M. De Ruijter \\ Institute for Marine and Atmospheric Research Utrecht \\ Utrecht University \\ Utrecht, the Netherlands
}

and

Andreas Sterl and Sybren S. Drijfhout

Royal Netherlands Meteorological Institute

De Bilt, the Netherlands

Submitted to: Global and Planetary Change

Revised version of February 2, 2001

Corresponding Author:

Wilbert Weijer

Institute for Marine and Atmospheric Research Utrecht

Department of Physics and Astronomy

Utrecht University

Princetonplein 5, 3584 CC Utrecht

The Netherlands

Phone: ++31-30-2537759; Fax: ++31-30-2543163

Email: W.Weijer@phys.uu.nl 


\begin{abstract}
The heat and salt input from the Indian to Atlantic Oceans by Agulhas Leakage is found to influence the Atlantic overturning circulation in a low-resolution Ocean General Circulation Model. The model used is the Hamburg Large-Scale Geostrophic (LSG) model, which is forced by mixed boundary conditions. Agulhas Leakage is parameterized by sources of heat and salt in the upper South Atlantic Ocean, that extend well into the intermediate layers.

It is shown that the model's overturning circulation is sensitive to the applied sources of heat and salt. The response of the overturning strength to changes in the source amplitudes is mainly linear, interrupted once by a stepwise change. The South Atlantic buoyancy sources influence the Atlantic overturning strength by modifying the basin-scale meridional density and pressure gradients. The nonlinear, stepwise response is caused by abrupt changes in the convective activity in the northern North Atlantic.

Two additional experiments illustrate the adjustment of the overturning circulation upon sudden introduction of heat and salt sources in the South Atlantic. The North Atlantic overturning circulation responds within a few years after the sources are switched on. This is the time it takes for barotropic and baroclinic Kelvin waves to reach the northern North Atlantic. The advection of the anomalies takes 3 decades to reach the northern North Atlantic.

The model results give support to the hypothesis that the re-opening of the Agulhas Gap at the end of the last ice-age, as indicated by palaeoclimatological data, may have stimulated the coincident strengthening of the Atlantic overturning circulation.
\end{abstract}


Keywords:

- thermohaline circulation

- climate

- ocean circulation

- South Atlantic 


\section{Introduction}

In the subpolar regions, the surface waters of the Atlantic are by far the saltiest in the World Ocean (e.g., Levitus 1982), and contrast strongly with surface waters in, for instance, the North Pacific. This contrast is thought to be one of the factors responsible for deep water being formed mainly in the North Atlantic, and not in the North Pacific (Warren 1983). The high salinities of the Atlantic thermocline waters are in general ascribed to the excess evaporation and associated freshwater export from the Atlantic basin, that is estimated at $0.7 \mathrm{~Sv}$ north of $35^{\circ} \mathrm{S}$ (Baumgartner and Reichel 1975).

Gordon $(1985,1986)$ was the first to recognize that the exchange of water between the South Indian and Atlantic Oceans might play a role in maintaining the high Atlantic surface salinities as well. This exchange, commonly known as Agulhas Leakage (Lutjeharms 1996; De Ruijter et al. 1999), is mainly accomplished by the shedding of large rings from the Agulhas Current in the so-called Agulhas Retroflection area. Filled with warm and salty Indian Ocean water, these rings subsequently drift into the South Atlantic, where they dissipate. The water entering the Atlantic through this leakage is saltier than the surrounding South Atlantic waters (Gordon et al. 1987). It is derived mainly from the evaporative subtropical Indian Ocean (Indian Ocean Central Water, Gordon et al. 1992), and it is subjected to strong evaporative activity in the Agulhas Retroflection area (Gordon et al. 1987; Van Ballegooyen et al. 1994). On the basis of this observation, Gordon et al. (1992) suggested that Agulhas Leakage could have dynamical impact on the meridional overturning circulation as well: the salt input salinifies the Atlantic surface waters and would precondition them for the formation of NADW. They even speculated: "if the Indian Ocean salt input were severed, might the NADW thermohaline cell run down?"

[Figure 1 about here.]

The answer to this question may have implications for the thermohaline circulation 
during the Pleistocene. De Ruijter (1982) has shown that the presence of Agulhas Leakage critically depends on the position of the Subtropical Convergence Zone (STCZ), that may be considered as the southern boundary of the wind-driven gyres of the South Indian and Atlantic Oceans. Compared to the present-day wind field, a northward shift of only a few degrees would suffice to effectively shut off the connection between the Subtropical Gyres of the South Indian and South Atlantic Oceans.

A study of planktonic foraminifera assemblages in several sediment cores from the South Indian Ocean (Howard and Prell 1992) indicates that the positions of the major Southern Ocean fronts have shifted considerably during the last 500 kyr. These shifts mainly reflect the major glacial-interglacial cycles. In particular, the STCZ was shifted several degrees northward during the glacial periods with respect to its present position at about $45^{\circ} \mathrm{S}$ (Fig. 1). Analysis of calcareous plankton assemblages from a core recovered from the Cape Basin (Flores et al. 1999) indicates that during glacial stages 2-4 and 6 the influence of the Agulhas Current on the basin was strongly reduced. This is consistent with a more northerly position of the STCZ, and an associated reduction of the leakage.

Berger and Wefer (1996) pointed out that the establishment of a firm Atlantic overturning circulation at the end of the last ice-age coincided with the reappearance of the foraminifera species Globorotalia menardii in the tropical Atlantic. This species had been extinct in the glacial Atlantic, but not in the Indian Ocean. Its reappearance can only be explained by reseeding of the Atlantic from the Indian Ocean, possibly in response to a reopening of the Agulhas connection. Bearing in mind the hypothesis of Gordon et al. (1992), Berger and Wefer (1996) speculated whether the reopening of Agulhas Leakage may have played a role in the sequence of events leading to the recovery of the overturning circulation.

Cai and Greatbatch (1995) were the first to address the hypothesis of Gordon et al. (1992) by comparing two models of the global ocean circulation; in one model Agulhas 
Leakage was present, whereas in the other it was inhibited by extending the African continent several degrees southward. They concluded that the strength of the Atlantic overturning circulation is unaffected by the presence or absence of Agulhas Leakage. However, Rahmstorf et al. (1996) pointed at the unrealistically weak thermal coupling between the ocean and atmosphere that was implied by the so-called zero heat capacity atmosphere model used by Cai and Greatbatch (1995). This severely hindered the development of density anomalies, and hence the pressure field was not affected. Furthermore, their approach did not allow for systematically varying the Agulhas exchange, and the robustness of the response was neither questioned nor tested.

Weijer et al. $(1999,2001)$ showed that under mixed boundary conditions (i.e., prescribed freshwater flux and relaxation of sea-surface temperature towards a prescribed profile) inter-ocean fluxes of heat and salt may influence the overturning circulation considerably. This type of surface forcing allows for the development of density anomalies, since thermal anomalies are rapidly damped while saline anomalies are unaffected. However, their model was highly simplified, and represented the overturning circulation in a 2D meridional-depth plane of the Atlantic Ocean. Consequently, it lacked realistic features that probably affect the sensitivity of the overturning circulation in the real ocean, like basin geometry and bathymetry, the wind-driven circulation and rotational effects. Furthermore, only steady states were calculated, so that the adjustment of the overturning circulation upon sudden changes in the inter-ocean exchange could not be studied.

In the present study, the question of the impact of Agulhas Leakage on the overturning circulation is addressed using the low-resolution Hamburg LSG model. Due to its coarse spatial resolution and high viscosity, the model does not resolve Agulhas Leakage under realistic wind stress forcing (Drijfhout et al. 1996). Therefore, the Agulhas heat and salt exchanges are parameterized by heat and salt sources in the South Atlantic (and equally large heat and salt sinks in the South West Indian Ocean, from which Ag- 
ulhas Leakage originates). In this way the thermohaline impact of Agulhas Leakage can be studied systematically, without explicitly affecting the momentum balance. It will be shown that in this model the Agulhas heat and salt sources affect the overturning strength by changing the large-scale density and pressure distributions (as suggested by the studies of Hughes and Weaver (1994) and Rahmstorf (1996)), rather than by changing the convective activity (as suggested by Gordon et al. (1992)). Additionally, the adjustment of the overturning circulation is studied to changes in the Agulhas source amplitudes. This will shed some light on the mechanisms that generate the response of the overturning circulation, and on their corresponding time scales.

The model is introduced in section 2. The spin-up procedure is described, and an evaluation is made of the circulation that is used as starting point for the experiments. The section concludes with a description of the source/sink parameterization that is used to model the Agulhas input of heat and salt. In section 3 the results of the main experiment are presented and analyzed, concerning an integration over $10 \mathrm{kyr}$. In section 4 the results of two adjustment experiments are analyzed. Section 5 discusses the implications of the results, and evaluates the Agulhas Leakage parameterization.

\section{The model}

\subsection{The Hamburg LSG model}

The Hamburg Large-Scale Geostrophic (LSG) model has been developed for climate studies, and it was described in detail in Maier-Reimer and Mikolajewicz (1992) and Maier-Reimer et al. (1993). In this model the fast modes have been filtered out by integrating the complete set of primitive equations with a semi-implicit time-stepping method, and by neglecting non-linear advection of momentum. This allows for a time step of 30 days. The model has a free-surface formulation, with a sea-surface height $(\zeta)$ 
that is prognostically determined. The ocean is coupled to a simple thermodynamic sea-ice model, and is forced by the wind-stress climatology of Hellerman and Rosenstein (1983). The model is discretized on an Arakawa E-grid (Arakawa and Lamb 1977). It has an effective horizontal resolution of $3.5^{\circ} \times 3.5^{\circ}$, and 11 vertical levels, centered at depths of 25, 75, 150, 250, 450, 700, 1000, 2000, 3000, 4000 and $5000 \mathrm{~m}$. For the momentum equations, the standard hydrostatic and Boussinesq approximations are applied, and vertical friction is neglected.

The fully non-linear UNESCO (1981) equation of state is used. Furthermore, a convective adjustment scheme is applied that interchanges unstably stratified pairs of layers in one downward sweep. This removes most, though not all, of the instabilities. Bryden's (1973) polynomial expression is used to convert the potential temperature $\theta$ to the in-situ temperature $T$ (Maier-Reimer et al. (1993) use a linearized equation). For reasons given below, a higher value of the viscosity $\left(4 \cdot 10^{5} \mathrm{~m}^{2} \mathrm{~s}^{-1}\right)$ is used in this study than the $5 \cdot 10^{4} \mathrm{~m}^{2} \mathrm{~s}^{-1}$ used by Maier-Reimer et al. (1993).

\subsection{The source distribution}

Heat and salt exchange by Agulhas Leakage takes place by the inflow of Indian Ocean water into the south-east Atlantic, and a compensating return transport leaving the Atlantic. The inflowing Indian Ocean water is characterized by higher temperatures and salinities than the surrounding South Atlantic thermocline waters. Based on this difference in water mass properties, Van Ballegooyen et al. (1994) estimated the heat and salt exchange by an average of 6 Agulhas rings per year at about 0.045 PW and 2.52 $\mathrm{Gg} / \mathrm{s}$. This is probably an underestimation: Agulhas Leakage is not only sustained by the shedding of large rings, but also by Agulhas Current water leaking directly into the Atlantic (Gordon et al. 1987), partly in the form of filaments (Lutjeharms and Cooper 1996). Moreover, the exact amount of heat and salt that is exchanged can only be 
determined when the temperature and salinity is known of the water that is exported to compensate for the Agulhas water input. If, for instance, a large part of the Agulhas inflow is compensated by outflow of NADW, then the corresponding heat flux may be up to an order of magnitude larger (Gordon 1985).

In this model, Agulhas heat and salt input is parameterized by sources of heat and salt in the South Atlantic Ocean (denoted by $q_{\text {Atlantic }}$ ). To close the heat and salt budgets, equal amounts of heat and salt are extracted from the south-west Indian Ocean, where the leakage originates $\left(q_{\text {Indian }}\right)$. The strength of the sources are controlled by a dimensionless amplitude $\sigma$, that relates the volume integrals of the sources to the original Van Ballegooyen et al. (1994) values:

$$
<q_{\text {Atlantic }}>=-<q_{\text {Indian }}>=\sigma Q_{\text {VanBallegooyen }},
$$

where the brackets denote volume integration. A value of $\sigma=1$ thus represents the original Van Ballegooyen et al. (1994) heat and salt exchange of 0.045 PW and 2.52 $\mathrm{Gg} / \mathrm{s}$, whereas $\sigma=10$ would be closer to Gordon's (1985) heat flux estimate.

[Figure 2 about here.]

The horizontal distribution of the sources in the South Atlantic (Fig. 2) reflects to some extent the corridor that is taken by the Agulhas Rings before they cross the Walvis Ridge (Byrne et al. 1995; Schouten et al. 2000). The sources thus represent the release of the anomalous heat and salt contents when Agulhas rings decay. The north-westerly part of the distribution coincides with the extension of the Benguela Current, that advects the released heat and salt further north. The heat and salt removal from the south-west Indian Ocean is distributed over the Agulhas Return Current and the South Indian Current. The sources decay exponentially with depth with an $e$-folding scale of $300 \mathrm{~m}$, so that the exchange taking place on intermediate levels is represented as well (Gordon et al. 1992). 


\subsection{The spin-up}

All the experiments are done with mixed boundary conditions, i.e., sea-surface temperature (SST) is restored towards a fixed temperature field, while the surface freshwater flux is prescribed. SST is restored to monthly mean air temperatures derived from COADs (Woodruff et al. 1987). An air-sea coupling coefficient of $40 \mathrm{Wm}^{2} \mathrm{~K}^{-1}$ is used, equivalent to a time constant of 58 days. In the first phase of the spin-up, sea-surface salinity (SSS) was restored to the annual mean climatology of Levitus (1982), with a time constant of 38 days. After $10 \mathrm{kyr}$ a steady solution was reached, and 10 years of the freshwater flux were diagnosed and averaged into an annual freshwater flux cycle. The model was run for another 1500 years with mixed boundary conditions.

[Figure 3 about here.]

The meridional overturning streamfunction (Fig. 3) shows a well developed NADW cell, and a well developed Antarctic Bottom Water (AABW) cell beneath it. The $18 \mathrm{~Sv}$ NADW production is close to Broecker's (1991) estimate of $20 \mathrm{~Sv}$, but the $9 \mathrm{~Sv}$ outflow is lower than the estimated $14 \mathrm{~Sv}$ (Schmitz 1995). This indicates that the model overestimates the NADW upwelling within the Atlantic. The overturning strength and NADW outflow are also smaller than the $23 \mathrm{~Sv}$ and $17 \mathrm{~Sv}$ found by Maier-Reimer et al. (1993). This difference is mainly caused by the smaller value of the viscosity used by them. A run with this same low viscosity yielded a $24 \mathrm{~Sv}$ overturning and a $15 \mathrm{~Sv}$ outflow, but the time it took to reach an equilibrium turned out to be much longer. Since our interest is largely qualitative, the higher value of the viscosity is used for the experiments presented here. 


\section{Slow source modification}

\subsection{Overturning response}

[Figure 4 about here.]

In this experiment, the amplitudes of the heat and salt sources are increased from 0 to 5 times the Van Ballegooyen et al. (1994) value, according to Eq. (1), in steps of 500 years (Fig. 4). After each dimensionless unit increase, $\sigma$ is kept constant for another 500 years to allow further equilibration of the solution. When $\sigma$ has reached the value of 5 at $4.5 \mathrm{kyr}$, it is kept constant for 1500 years, and it is decreased again during the following 2500 years.

The time scale with which the source amplitude is increased is longer than the adjustment time scale of the flow. This adjustment time is in the order of a decade (Gill 1982, p. 510). This allows for a continuous balance in the momentum equations, and a well-equilibrated circulation. However, the time scale for the thermohaline fields to equilibrate is much longer than these 500 years. The vertical diffusivity is typically in

the order of $5 \cdot 10^{-4} \mathrm{~m}^{2} \mathrm{~s}^{-1}(\sim|w| \Delta z$ for the first-order upwind scheme), and corresponds to a vertical diffusive time scale of about 1600 years. So it cannot be expected that the tracer fields are fully balanced. Nevertheless, it will be shown that the adjustment of the flow is very weak during the phases of the experiment in which the source amplitudes are constant: the final equilibration phases of the thermohaline fields do not impose large changes on the flow field after the initial adjustment.

[Figure 5 about here.]

The overturning circulation displays a particularly strong response to changes in the Agulhas heat and salt source amplitudes, i.e., roughly a $10 \mathrm{~Sv}$ increase in both production and outflow for a source strength of 5 . Figure 5 shows that the relation between the 
production and outflow of NADW and the source amplitude is mainly linear: except for the events at 2.5 and $7.5 \mathrm{kyr}$, when both production and outflow of NADW show stepwise adjustments, the shape of the source amplitude evolution (Fig. 4) is clearly reproduced in the response of the overturning circulation. The overturning strength also displays a non-linear response: at 2.5 and $7.5 \mathrm{kyr}$, both the NADW production and outflow show stepwise adjustments.

\subsection{Linear response}

[Figure 6 about here.]

Figure 6 shows that the NADW production is linearly related to the meridional pressure difference, integrated over the upper $1500 \mathrm{~m}$. This suggests that an increase of the source amplitudes stimulates the overturning circulation by enhancing the meridional gradients of the large-scale pressure field. Near the source area, the heat and salt sources generate only a weak positive density anomaly that is confined to the near-surface layers. Here, the development of the thermal anomaly is inhibited by strong surface relaxation, whereas at depth the thermal and saline anomalies compensate with respect to their effect on density. On its way north, the thermal anomaly is more and more attenuated by atmospheric heat loss, and the density anomaly is amplified. The resulting meridional gradient in the anomalous density field enhances the (positive) meridional gradient in the baroclinic pressure field. This generates an anomalous (depth-dependent) southward transport, for reasons that will be discussed below. Due to this southward flow, sealevel in the North Atlantic drops and strengthens the (negative) meridional gradient of the barotropic pressure field. This generates the northward transport that is needed to balance the enhanced southward flow: strengthening of the gradient in the barotropic pressure field reduces the anomalous pressure gradient and southward transport at depth (below the anomaly), and generates an anomalous pressure gradient and northward flow 
at shallower levels (Fig. 6).

[Figure 7 about here.]

[Figure 8 about here.]

The linear relation between overturning strength and meridional pressure difference, as implied by Fig. 6, suggests that the north-south pressure imbalance is directly imparted onto the meridional circulation. In the ocean, where the flow is mainly geostrophically controlled, the meridional transport must be balanced by zonal pressure gradients instead (e.g., Klinger and Marotzke 1999). In our model, however, such a geostrophic relation does not exist for the anomalous (zonally averaged) overturning circulation. Figure 7 shows that the geostrophically balanced component of the northward transport across $30^{\circ} \mathrm{S}$ is more or less constant during the experiment. The Coriolis force working on the remaining (anomalous) component of the meridional transport must be balanced by friction, since no other forces are present. Indeed, the enhanced transports are concentrated in the western boundary layers (Fig. 8), where friction is a first-order term in this low-resolution model.

\subsection{Non-linear response}

[Figure 9 about here.]

Analysis of the output fields reveals that the change in overturning strength at $2.5 \mathrm{kyr}$ is accompanied by a sudden increase in convective activity in the northern North Atlantic, and a westward expansion of the convecting area. At $7.5 \mathrm{kyr}$, the reverse happens, and the convective activity is strongly reduced. The sudden changes in convective activity are clearly reflected by jumps in the convective vertical transports of heat (Fig. 9) and salt (not shown). 
The abruptness of the response suggests that a shift in convective activity is triggered when a certain threshold is exceeded. This threshold is related to the stratification in the North Atlantic, and causes a marginally stable area to become unstable and viceversa (not shown, Lenderink and Haarsma 1994). The upward shift at 2.5 kyr takes place when the source amplitude $\sigma$ has reached the value of 3 , while the downward shift at $7.5 \mathrm{kyr}$ takes place at $\sigma=2$ (Fig. 9). This hysteresis behavior shows that for $2<\sigma<3$ several (at least two) equilibria coexist for the same forcing conditions. Note that the overturning strength is about $23 \mathrm{~Sv}$ both at the time of the upward and downward jumps in the convective intensity. This means that there is no hysteresis of the abrupt changes in convective activity with respect to overturning strength.

\section{Fast source modification}

In the slow source experiment, the South Atlantic sources were increased slowly to avoid large disturbances of the equilibrium. In this section we study the fast adjustment of the circulation, by performing two switch-on experiments in which the South Atlantic sources are changed abruptly. To avoid destabilization of the density stratification in the source area, only source configurations with negative or neutral density input are applied. This protects the deeper layers from spurious ventilation, so that only the shallower layers are affected by the heat and salt sources. Both experiments are started from the solution of the slow source experiment at $2 \mathrm{kyr}$, where both the heat and salt sources have an amplitude of 2 . The two runs are compared with a reference run in which the source amplitudes are not changed. In the first experiment only the salinity field is perturbed by suddenly reducing the salt source amplitude from 2 to 1 . This is equivalent to applying an instantaneous source of freshwater. In the second experiment a sudden heat and salt source is applied by increasing the amplitudes of both the heat and salt sources from 2 to 3 . 


\subsection{Dispersion of the perturbation}

[Figure 10 about here.]

Figure 10 shows the dispersion of the salinity anomaly in the freshwater source experiment. Once created in the source region, the salinity anomaly is picked up by the (model-equivalent of the) North Brazil Current, and enters the interior of the North Atlantic through the Gulf Stream and the North Atlantic Current. It takes about 30 years for the anomaly to reach the northern part of the North Atlantic. This is in agreement with the advective time-scale, since it takes about 30 years to advect an anomaly over a distance of $10^{7} \mathrm{~m}$ by a velocity of $10^{-2} \mathrm{~m} \mathrm{~s}^{-1}$, which is characteristic for the wind-driven gyres.

[Figure 11 about here.]

Figure 11 shows that a density anomaly reaches the North Atlantic much faster. In the first year the density anomaly develops in the South Atlantic, and reaches the Brazilian coast in the second year. In the third year the density anomaly crosses the Atlantic within the equatorial wave guide, and then propagates poleward in both the North and South Atlantic Oceans. In the same year, it reaches $35^{\circ} \mathrm{N}$ and $35^{\circ} \mathrm{S}$, propagating with a speed of more than $0.12 \mathrm{~m} / \mathrm{s}$. In the subsequent years the propagation slows down to about $0.05 \mathrm{~m} / \mathrm{s}$ at the higher latitudes, and the disturbance reaches the northern North Atlantic in year 6. On its way poleward, the density disturbance radiates Rossby wave-like features into the interior of the basins.

The adjustment of the ocean to disturbances in the buoyancy field has been studied before (e.g., Kawase 1987; Döscher et al. 1994; Huang et al. 2000; Hirschi et al. 2001). As in these studies, the signal in Fig. 11 shares characteristics with baroclinic Kelvin waves (e.g., Gill 1982): it causes vertical displacement of isopycnals and propagates with the coastal boundary on the right (left) in the northern (southern) hemisphere. 
The slower wave propagation at higher latitudes reflects the fact that the stratification weakens towards higher latitudes (Levitus 1982; Hirschi et al. 2001), thus reducing the phase speed of internal gravity waves. However, Gill (1982, p. 379) estimated that in the ocean the phase velocity of these waves is in the order of $3 \mathrm{~m} \mathrm{~s}^{-1}$ at mid-latitudes. This estimate is at least one order of magnitude higher than the propagation speeds found here. The most probable reason for the slow wave propagation is the bad numerical representation of these waves in viscous, low-resolution models (Hsieh et al. 1983). Our model probably underestimates the wave propagation by an order of magnitude, so that in reality, a density anomaly would reach the northern North Atlantic within a year.

\subsection{Overturning response}

[Figure 12 about here.]

The response of the (anomalous) NADW production and NADW outflow across $30^{\circ} \mathrm{S}$ upon introducing the freshwater source in the South Atlantic is shown in Fig. 12a. Clearly, there is an immediate and steady decrease in the NADW outflow. The NADW production, on the other hand, increases initially, and starts to decrease only after about 25 years. At this time, the (anomalous) meridional pressure difference in the upper 1500 m changes sign as well (Fig. 12b).

[Figure 13 about here.]

The evolution of the anomalous overturning streamfunction (Fig. 13) shows that the freshwater source initially generates a convergence at depth, since it lowers the baroclinic pressure beneath the anomaly. This convergence reduces the deep export of NADW (Fig. 12a). It raises the sea level and increases the associated barotropic component of the pressure, forcing divergence at shallower levels. The reduction of the baroclinic pressure beneath the anomaly enhances the pressure difference at depth with respect to 
the North Atlantic, whereas the increased barotropic pressure enhances the (negative) meridional pressure difference at shallower levels (Fig. 12b). This explains the initial increase in the overturning strength.

In the course of time, the fresh anomaly disperses northward (Fig. 10) and the thermocline salinities are homogenized. The anomalous meridional density gradient is consequently reduced, and the anomalous baroclinic pressure gradient weakens (Fig. 12b, dotted line). Also the anomaly in the barotropic pressure field declines (Fig. 12b, dashed line), but much more rapidly than its baroclinic counterpart. The sum of these components, i.e., the anomalous meridional pressure gradient (in the upper $1500 \mathrm{~m}$ ), changes sign after 25 years, and marks the transition from enhanced to reduced NADW formation.

[Figure 14 about here.]

Why the anomalous meridional pressure gradient and the associated overturning strength decline so rapidly cannot be explained by processes within the Atlantic alone. It seems that here the interaction between the Atlantic and the Southern Ocean plays a role: when the Atlantic becomes fresher, the baroclinic pressure within the entire Atlantic is lowered, and the pressure contrast at depth with regions outside the Atlantic is reduced (Fig. 14, solid line). This reduces the outflow across $30^{\circ} \mathrm{S}$, and, in turn, increases the barotropic pressure within the Atlantic. This forms a barrier for shallow extra-Atlantic water entering the South Atlantic (Fig. 14, dashed line). In fact, this emphasizes the global character of the thermohaline circulation, and the importance of Atlantic/Southern Ocean interaction for the Atlantic overturning circulation.

The North Atlantic overturning circulation responds within two years to density disturbances in the South Atlantic (Fig. 12a). According to Fig. 10, it takes between 20 and 30 years for a disturbance to reach the North Atlantic by advection. Baroclinic Kelvin waves take 5 or 6 years to reach the northern North Atlantic in this model 
(Fig. 11). The signal generated in the South Atlantic must have reached the North Atlantic through barotropic Kelvin waves, since no other mechanism is able to transmit information over the whole Atlantic in less than two years.

[Figure 15 about here.]

In the heat and salt source experiment, the response of the NADW production and outflow rate (Fig. 15) differs markedly from that of the freshwater source experiment. Now the change in the NADW production leads the change in the outflow by more than a decade.

[Figure 16 about here.]

The difference between the response of the circulation to applying a freshwater source and a combined heat and salt sources is mainly caused by a different evolution of the anomalous density field (Fig. 16). In the freshwater source experiment, the largest density anomaly develops in the South Atlantic, generating a strong anomalous meridional density gradient in the initial stages of the experiment. In the course of time, this density gradient reduces considerably when the fresh anomalies disperse through the entire Atlantic thermocline. In the heat and salt source experiment, on the other hand, the density anomaly develops in the north. In the source area, the thermal and saline anomalies almost cancel with respect to their effect on density, and no density anomaly is generated in the first stages of the experiment. When the anomalies are advected northward, the thermal anomaly is removed by air-sea fluxes, and the density anomaly is amplified. Indeed, a significant anomaly in the meridional pressure gradient only develops on the advective time scale of several decades (Fig. 15b). The strength of the overturning circulation increases accordingly. As in the freshwater source experiment, the anomalous barotropic meridional pressure gradient develops stronger than its baroclinic counterpart, indicating interaction with the Southern Ocean: the increasing 
salinity of the Atlantic enhances the pressure contrast at depth between the Atlantic and the Southern Ocean, stimulating the outflow of NADW (not shown).

As in the slow source experiment, the relation between the anomalous overturning and the meridional pressure difference (integrated over the upper $1500 \mathrm{~m}$ ) in the two fast source experiments is linear, and exhibits the same sensitivity of approximately 10 $\mathrm{Sv} \mathrm{Pa}^{-1} \mathrm{~m}^{-1}$.

\section{Discussion}

In this paper we have shown that buoyancy sources in the South Atlantic are able to influence the Atlantic overturning circulation in a coarse-resolution OGCM forced with mixed boundary conditions. These results support the hypothesis of Gordon et al. (1992) that Agulhas Leakage influences the overturning circulation. However, the physical mechanism they proposed is not responsible for the dominant (linear) response of the overturning strength to Agulhas Leakage. In their hypothesis, Agulhas salt input would precondition the Atlantic thermocline waters for deep convection, and thereby stimulate the production rate of NADW. In our experiments, however, the overturning circulation responds to changes in the Agulhas source amplitudes, without a gradual increase in convective activity. Moreover, the adjustment experiments show that the overturning strength responds to applying South Atlantic buoyancy sources before a thermohaline anomaly has reached the convective areas.

The model experiments show a clear linear relation between the overturning strength and the meridional pressure gradient. This points to a scenario where the Agulhas heat and salt sources modify the overturning circulation by influencing the meridional pres-

sure gradients. A linear relation between the overturning strength and characteristics of the meridional density gradient has been found before in global ocean models (Hughes and Weaver 1994; Rahmstorf 1996). It was furthermore shown that the meridional 
transports are not balanced by zonal pressure gradients, but by friction, and that overturning fluctuations take place mainly in the western boundary layers.

Changes in convective activity are responsible for a non-linear response of the overturning strength: sudden changes in the overturning strength coincided with sudden modifications of the convective activity, and spatial redistributions of the convective regions. Between the source strength amplitudes 2 and 3 two equilibria were found to be stable. Several studies have shown (Lenderink and Haarsma 1994; Rahmstorf 1994, 1995) that the convective adjustment procedure in Ocean General Circulation Models (OGCMs) may give rise to the coexistence of several equilibria that differ only in the intensity and the spatial distribution of the convective activity. It is probable that these multiple equilibria are an artifact of the convective adjustment procedure (Vellinga 1998), which is an ad-hoc representation of a process (mesoscale convection) that cannot be resolved by these models. It is therefore not likely that the non-linear response in this model study is robust with respect to model details like the convective adjustment algorithm and grid spacing. Nonetheless, observations show that in the real ocean shifts do occur in the convective activity from one area in the ocean to another. It has, for instance, been observed that from the late 80's onwards the convective intensity in the Labrador Sea increased in strength, whereas the convective activity in the Greenland seas declined (Dickson et al. 1996; Marshall and Schott 1999).

In this model, the heat and salt exchange brought about by Agulhas Leakage was parameterized by sources of heat and salt in the South Atlantic Ocean, and equally large sinks in the south-west Indian Ocean. The horizontal distribution of the sources in the South Atlantic were chosen to reflect the Agulhas Rings corridor (Byrne et al. 1995; Schouten et al. 2000), i.e., the initial path that is taken by most of the rings before they cross the Walvis Ridge. The source distributions were thus placed diagonally over the South Atlantic. We expect that the spatial characteristics of the source distributions are important for the response of the overturning circulation, since they determine to 
a large extent the changes in the density and pressure fields. To test this idea, the combined heat and salt source adjustment experiment was repeated with a zonally oriented source distribution. This experiment showed that the adjustment process was indeed modified. The development of $P_{S}$ occurred in a similar fashion as in Fig. 15, but $P_{N}$ developed very slowly. The response in the overturning strength was accordingly weak and retarded with respect to the original adjustment experiment. Obviously, the diagonal orientation of the original source distribution, with anomalies developing in the northward flowing Benguela Current, stimulates an efficient northward transport and enhancement of the density anomalies.

The results of this study suggest that, for Agulhas Leakage to have impact on the Atlantic overturning circulation, it is necessary to have different attenuation time scales of the thermal and saline anomalies (Stommel 1961). Only then may density anomalies develop that modify the pressure distribution in the Atlantic and influence the overturning strength. This explains why Cai and Greatbatch (1995) found no influence of Agulhas Leakage on the Atlantic overturning circulation: according to Rahmstorf et al. (1996), the thermal relaxation of Cai and Greatbatch (1995) was unrealistically weak, and caused too little distinction between the evolution of the thermal and saline anomalies for density anomalies to develop. In this model the circulation was forced with so-called mixed boundary conditions: a freshwater flux was prescribed, and a Newtonian relaxation condition was applied to the sea-surface temperature. However, mixed boundary conditions over-simplify the interaction of the ocean with the atmosphere, and are known to over-estimate the sensitivity of the response to disturbances (e.g., Rahmstorf and England 1997). It is therefore likely that models that include more feedbacks between the ocean and atmosphere will show a modified sensitivity of the overturning strength to Agulhas sources than found here. But as long as they predict distinctively different lifetimes for thermal and saline anomalies, an impact on the overturning circulation can be expected. 
The results support the hypothesis of Berger and Wefer (1995) that the simultaneous re-opening of the Agulhas gap and the recovery of the Atlantic overturning circulation at the end of the last ice-age may have been more than coincidental. A sudden increase in heat and salt input from the Indian Ocean into the Atlantic Ocean may have influenced the overturning strength in the Atlantic within decades. On palaeoclimatological timescales, this response is immediate, so that an accurate determination of the timing of both events from palaeoceanographic data may not be conclusive to validate or reject the hypothesis. Furthermore, in this model the response is mainly confined to the western boundary layers, so that in these regions the timing of changes in the overturning circulation is probably most accurately recorded. It also implies that the interior ocean may to some degree be isolated from changes in the thermohaline circulation, so that recorded changes in the interior ocean circulation are not simply related to changes in the overturning circulation.

\section{Summary and conclusions}

In this paper we investigate how Agulhas Leakage influences the Atlantic overturning circulation in a General Circulation Model. To this end, the Hamburg LSG model was integrated for $10 \mathrm{kyr}$. Agulhas Leakage heat and salt exchange were parameterized by prescribing sources of heat and salt in the upper $1000 \mathrm{~m}$ of the South Atlantic. This allowed for a systematic investigation of the impact of this thermohaline exchange on the strength of the overturning circulation.

The overturning circulation responded strongly to gradual changes in the amplitude of the applied sources. The response was mainly linear, and displayed a sensitivity of roughly $2 \mathrm{~Sv}$ (or about $10 \%$ of the basic overturning) per unit increase in source amplitude (with respect to present-day fluxes). It turned out that the South Atlantic buoyancy sources influence the Atlantic overturning circulation by modifying the basin- 
scale meridional density and pressure gradients. During the experiment the overturning strength also adjusted stepwise to the gradual changes in the source amplitudes. This non-linear response resulted from a switch between two equilibria, differing in the intensity and distribution of the North Atlantic convective activity. The results thus support the hypothesis of Gordon et al. (1992) that Agulhas Leakage stimulates the thermohaline circulation, albeit through a different mechanism.

Two switch-on experiments revealed that the Atlantic overturning circulation can respond within 2 years on a density perturbation in the South Atlantic. This information reaches the North Atlantic through barotropic Kelvin waves. In this model, baroclinic Kelvin waves reached the North Atlantic in less than 6 years, but it is likely that these time scales are considerably shorter in the real ocean. The strongest response set in when the density anomaly reached the North Atlantic by advection. This took about 3 decades. Obviously, given the limitations of this model, these time scales give only rough estimates.

The adjustment experiments also emphasized the importance of the different attenuation time scales of thermal and saline anomalies in generating density anomalies. Although Agulhas heat and salt input initially balance with respect to their effect on density, it is due to the strong thermal relaxation that a density anomaly can develop on its way north. Although mixed boundary conditions probably overestimate this difference, and coupled models will produce more reliable estimates, an impact on the overturning circulation can be expected as long as distinctively different life times for thermal and saline anomalies are predicted.

We may conclude that our model results support the hypothesis of Berger and Wefer (1996) that the reopening of the Agulhas gap at the end of the last ice-age may have played a role in the restart of the Atlantic overturning circulation. 


\section{Acknowledgments}

WW and WR were supported by the Dutch National Research Programme on Global Change (NRP II) under grant 013001237.10. The authors thank two anonymous reviewers for useful comments. WW and WR thank Henk Dijkstra and Peter Jan van Leeuwen for useful discussions. 


\section{References}

Arakawa, A., and V. R. Lamb, 1977: Computational design of the basic dynamical processes of the UCLA General Circulation Model. Methods. Comput. Phys., 17, $173-265$.

Baumgartner, A., and E. Reichel, 1975: The world water balance, Elsevier, 179 pp.

Berger, W. H., and G. Wefer, 1996: Late quaternary movements of the AngolaBenguela Front, SE Atlantic, and implications for advection in the equatorial ocean. In: G. Wefer, W. H. Berger, G. Siedler, D. J. Webb (Eds.), The South Atlantic: present and past circulation, Springer, Berlin, 363-410.

Broecker, W. S., 1991: The great ocean conveyor. Oceanogr., 4, 79-89.

Bryden, H. L., 1973: New polynomials for thermal expansion, adiabatic temperatuire gradient, and potential temperature gradient of sea water. Deep-Sea Res., 20, 401-408.

Byrne, D. A., A. L. Gordon and W. F. Haxby, 1995: Agulhas eddies: a synoptic view using Geosat ERM data. J. Phys. Oceanogr., 25, 902-917.

Cai, W., and R. J. Greatbatch, 1995: Compensation for the NADW outflow in a Global Ocean Circulation Model. J. Phys. Oceanogr., 25, 226-241.

De Ruijter, W. P. M., 1982: Asymptotic analysis of the Agulhas and Brazil Current systems. J. Phys. Oceanogr., 12, 361-373.

De Ruijter, W. P. M., A. Biastoch, S. S. Drijfhout, J. R. E. Lutjeharms, R. P. Matano, T. Pichevin, P. J. van Leeuwen and W. Weijer, 1999: Indian-Atlantic inter-ocean exchange: Dynamics, estimation and impact. J. Geophys. Res., 104, 2088520910. 
Dickson, R. R., J. Lazier, J. Meincke, P. Rhines and J. Swift, 1996: Long-term coordinated changes in the convective activity of the North Atlantic. Prog. Oceanogr., 38, 241-295.

Döscher, R., C. W. Böning and P. Herrmann, 1994: Response of circulation and heat transport in the North Atlantic to changes in thermohaline forcing in northern latitudes: a model study. J. Phys. Oceanogr., 24, 2306-2320.

Drijfhout, S. S., E. Maier-Reimer and U. Mikolajewicz, 1996: Tracing the conveyor belt in the Hamburg LSG ocean general circulation model. J. Geophys. Res., 101, $22563-22575$.

Flores, J.-A., R. Gersonde and F. J. Sierro, 1999: Pleistocene fluctuations in the Agulhas Current Retroflection based on the calcaeous plankton record. Marine Micropaleontology, 37, 1-22.

Gill, A. E., 1982. Atmosphere-Ocean Dynamics. Academic Press, 666 pp.

Gordon, A. L., 1985: Indian-Atlantic transfer of thermocline water at the Agulhas Retroflection. Science, 227, 1030-1033.

Gordon, A. L., 1986: Interocean exchange of thermocline water. J. Geophys. Res., 91, $5037-5046$.

Gordon, A. L., J. R. E. Lutjeharms and M. L. Gründlingh, 1987: Stratification and circulation at the Agulhas Retroflection. Deep-Sea Res., 34, 565-599.

Gordon, A. L., R. F. Weiss, W. M. Smethie Jr. and M. J. Warner, 1992: Thermocline and intermediate water communication between the South Atlantic and Indian Oceans. J. Geophys. Res., 97, 7223-7240.

Hellermann, S., and M. Rosenstein, 1983: Normal monthly wind stress over the World Ocean with error estimates. J. Phys. Oceanogr., 13, 1093-1104. 
Hirschi, J., J. Sander and T. F. Stocker, 2001: Fast interhemispheric teleconnections in an OGCM. J. Phys. Oceanogr., submitted.

Howard, W. R., and W. L. Prell, 1992: Late quaternary surface circulation of the southern Indian Ocean and its relationship to orbital variations. Paleoceanogr., $7,79-117$.

Hsieh, W. W., M. K. Davey and R. C. Wajsowicz, 1983: The free Kelvin wave in finite-difference numerical models. J. Phys. Oceanogr., 13, 1383-1397.

Huang, R. X., M. A. Cane, N. Naik and P. Goodman, 2000: Global adjustment of the thermocline in response to deepwater formation. Geophys. Res. Lett., 27, $759-762$.

Hughes, T. M. C., and A. J. Weaver, 1994: Multiple equilibria of an asymmetric two-basin ocean model. J. Phys. Oceanogr., 24, 619-637.

Kawase, M., 1987: Establishment of deep ocean circulation driven by deep-water production. J. Phys. Oceanogr., 17, 2294-2317.

Klinger, B. A., and J. Marotzke, 1999: Behavior of double hemisphere thermohaline flows in a single basin. J. Phys. Oceanogr., 29, 382-399.

Lenderink, G., and R. J. Haarsma, 1994: Variability and multiple equilibria of the thermohaline circulation associated with Deep-Water formation. J. Phys. Oceanogr., 24, 1480-1493.

Levitus, S., 1982: Climatological Atlas of the World Ocean. NOAA Prof. Paper No. 13, U.S. Govt. Printing Office, 173 pp.

Lutjeharms, J. R. E., 1996: The exchange of water between the South Indian and South Atlantic Oceans. The South Atlantic: present and past circulation, G. Wefer et al., Eds., Springer, 125-162. 
Lutjeharms, J. R. E. and J. Cooper, 1996: Interbasin leakage through Agulhas current filaments. Deep-Sea Res., 43, 213-238.

Maier-Reimer, E., and U. Mikolajewicz, 1992: The Hamburg Large-Scale Geostrophic Ocean General Circulation Model (cycle 1). DKRZ Tech. Rep. No. 2, 34 pp.

Maier-Reimer, E., U. Mikolajewicz, and K. Hasselmann, 1993: Mean circulation of the Hamburg LSG OGCM and its sensitivity to the thermohaline surface forcing. $J$. Phys. Oceanogr., 23, 731-757.

Marshall, J., and F. Schott, 1999: Open-ocean convection: observations, theory, and models. Rev. Geophys., 37, 1-64.

Rahmstorf, S., 1994: Rapid climate transitions in a coupled ocean-atmosphere model. Nature, 372, 82-85.

Rahmstorf, S., 1995: Multiple convection patterns and thermohaline flow in an idealized OGCM. J. Clim., 8, 3028-3039.

Rahmstorf, S., 1996: On the freshwater forcing and transport of the Atlantic thermohaline circulation. Climate Dyn., 12, 799-811.

Rahmstorf, S., and M. H. England, 1997: Influence of southern hemisphere winds on North Atlantic Deep Water flow. J. Phys. Oceanogr., 27, 2040-2054.

Rahmstorf, S., J. Marotzke and J. Willebrand, 1996: Stability of the thermohaline circulation. The warm water sphere of the North Atlantic, W. Krauss, Ed., Bornträger, 129-158.

Schmitz Jr., W. J., 1995: On the interbasin-scale thermohaline circulation. Rev. Geophys., 33, 151-173. 
Schouten, M. W., W. P. M. de Ruijter, P. J. van Leeuwen and J. R. E. Lutjeharms, 2000: Translation, decay and splitting of Agulhas rings in the south-eastern Atlantic Ocean. J. Geophys. Res., 105, 21913-21925.

Stommel, H., 1961: Thermohaline convection with two stable regimes of flow. Tellus, 13, 224-230.

UNESCO, 1981: Tenth report of the joint panel on oceanographic tables and standards. UNESCO Tech. Pap. in Mar. Sci. No. 36. UNESCO, Paris.

Van Ballegooyen, R. C., M. L. Gründlingh and J. R. E. Lutjeharms, 1994: Eddy fluxes of heat and salt from the southwest Indian Ocean into the southeast Atlantic Ocean: a case study. J. Geophys. Res., 99, 14053-14070.

Vellinga, M., 1998: Multiple equilibria in ocean models as a side effect of convective adjustment. J. Phys. Oceanogr., 28, 621-633.

Warren, B. A., 1983: Why is no deep water formed in the North Pacific? J. Mar. Res., 41, 327-347.

Weijer, W., W. P. M. de Ruijter, H. A. Dijkstra and P. J. van Leeuwen, 1999: Impact of interbasin exchange on the Atlantic overturning circulation. J. Phys. Oceanogr., 29, 2266-2284.

Weijer, W., W. P. M. de Ruijter and H. A. Dijkstra, 2001: Stability of the Atlantic overturning circulation: Competition between Bering Strait freshwater flux and Agulhas heat and salt sources. J. Phys. Oceanogr., in press.

Woodruff, S. D., R. J. Slutz, R. L. Jenne and P. M. Steurer, 1987: A comprehensive ocean-atmosphere data set. Bull. Amer. Meteor. Soc., 68, 1239-1250. 


\section{List of Figures}

1 The latitudinal position of the $10^{\circ} \mathrm{C}$, the $8^{\circ} \mathrm{C}$ and the $4^{\circ} \mathrm{C}$ isotherms in the Indian Ocean during the last $500 \mathrm{kyr}$, as inferred from foraminifera assemblages. These isotherms may be associated with the Subtropical Convergence, the Subantarctic Front and the Antarctic Polar Front, respectively. Shaded intervals indicate interglacial conditions. The arrows on the right indicate the present-day positions of the isotherms. They show that, for instance, the Subtropical Convergence $\left(10^{\circ} \mathrm{C}\right)$ was shifted northward during glacial times. This may have caused a considerable reduction in Agulhas Leakage. (Redrafted from Howard and Prell 1992).

2 Horizontal distribution of the heat and salt sources in the Atlantic (light grey area) and sinks in the Indian (dark grey area) Oceans. Superimposed are streamlines at $150 \mathrm{~m}$ depth of the spin-up solution. The source/sink distributions represent the exchange of heat and salt between the Indian and Atlantic Oceans by Agulhas Leakage. . . . . . . . . . . . . . . 36

3 Meridional overturning streamfunction of the spin-up solution in the Atlantic. . . . . . . . . . . . . . . . 37

4 Dimensionless source amplitude $\sigma$ as function of time as applied in the slow source experiment. A value of 1 accounts for the original Van Ballegooyen et al. (1994) values (0.045 PW for heat and $2.52 \mathrm{Gg} / \mathrm{s}$ for salt). 38 
5 Response of (a) the NADW production and (b) the NADW outflow across $30^{\circ} \mathrm{S}$ for the slow source experiment. The amplitudes of the Agulhas heat and salt sources are changed according to Fig. 4. 'NADW production' is defined as the maximum value of the zonally integrated overturning streamfunction in the North Atlantic. It measures the strength of the Atlantic overturning circulation. 'NADW outflow' is defined as the maximum value of the streamfunction at $30^{\circ} \mathrm{S}$, and measures the outflow of that component of NADW that is derived from surface waters, rather than from AABW. The variability during the first $0.5 \mathrm{kyr}$ and the last 2 kyr reflects an oscillation in the Southern Ocean, particularly influencing the NADW outflow. . . . . . . . . . . . . . . . . . 39

6 NADW production as function of the total (i.e., including $\rho_{0} g \zeta$ ) meridional pressure difference, measured by $\Delta P_{N S} . \Delta P_{N S}=P_{N}-P_{S}=$ $P\left(53^{\circ} N\right)-P\left(30^{\circ} S\right)$, where $P(\theta) \equiv \int_{-1500}^{0} \bar{p} d z$, with $\bar{p}$ the zonally averaged pressure at latitude $\theta$. . . . . . . . . . . . . . . . . . . 40

$7 \quad$ Northward transport across $30^{\circ} \mathrm{S}$ in the upper $1500 \mathrm{~m}$ (solid line) and its geostrophically balanced component (dashed line). Note that sample frequency is 1 per $100 \mathrm{yr}$. . . . . . . . . . . . . . . . 41

8 Velocity anomaly (in $\mathrm{cm} \mathrm{s}^{-1}$ ) at $3.5 \mathrm{kyr}$ (with respect to $\mathrm{t}=0$ ) at $150 \mathrm{~m}$ and $3000 \mathrm{~m}$. The enhanced overturning circulation is clearly concentrated in the (viscous) western boundary layers. . . . . . . . . . . . . . . . . . 42 
9 Strength of the convective activity as a function of the source amplitude $\sigma$ during the slow source experiment. Convective activity is measured by the upward convective heat transport, integrated over the Atlantic $\left(C^{\theta}=<z q_{\text {convection }}^{\theta}>\right.$, where $q_{\text {convection }}$ is the source/sink distribution implied by the convective adjustment procedure). Starting at $0 \mathrm{kyr}$, $C^{\theta}$ remains constant for the first $2.5 \mathrm{kyr}$ (indicated by the arrow). At $\sigma=3$, the solution jumps to a higher level of $C^{\theta}$ (corresponding to the expansion of the convective areas). This level is maintained for $5 \mathrm{kyr}$. When $\sigma=2(7.5 \mathrm{kyr})$, the solution returns to a lower value, indicating hysteresis behavior. Note that the solutions at 0 and $10 \mathrm{kyr}$ also display slightly different convective intensities. . . . . . . . . . . . . . . 43

10 Six snapshots of the annually averaged salinity anomaly $\left(\Delta S=S_{\text {source }}-\right.$ $S_{\text {main }}$ in $\mathrm{psu}$ ) at $250 \mathrm{~m}$ depth in the freshwater source experiment. The freshwater source, turned on in year 1, creates a negative salinity anomaly that is slowly advected northward along the east coast of the American continents. It reaches the northern North Atlantic within 30 years. . . . . 44

11 Six snapshots of the annually averaged density anomaly $\left(\Delta \rho=\rho_{\text {source }}-\right.$ $\rho_{\text {main }}$ in $10^{-3} \mathrm{~kg} \mathrm{~m}^{-3}$ ) at $450 \mathrm{~m}$ depth in the freshwater source experiment. The freshwater source, turned on in year 1, generates a negative density anomaly that radiates a wave-like signal. This signal reaches the equator already in year 2, and crosses the Atlantic via the equatorial wave guide between year 2 and 3. From there, the signal propagates rapidly poleward, along the continental margin. This behavior is characteristic for (the numerical equivalents of) Kelvin waves. The resulting coastally trapped anomalies radiate westward into the interior of the Atlantic. . . 45 
12 a) Anomalous NADW formation and NADW outflow across $30^{\circ} \mathrm{S}$ (with respect to the reference run) in the first adjustment experiment. In this experiment a freshwater source is switched on in the South Atlantic in year 1. b) Anomalous (negative) meridional pressure difference $-\Delta P_{N S}$ (as defined in Fig. 6, i.e., meridional difference of zonally averaged pressure, vertically integrated over the upper $1500 \mathrm{~m}$ ) and its barotropic and baroclinic contributions. Note that here $P_{S}=P\left(15^{\circ} \mathrm{S}\right)$, so that $P_{S}$ is diagnosed north of the anomalous upwelling region at $25^{\circ} \mathrm{S}$ (Fig. 13). . . 46

13 Six snapshots of the streamfunction anomaly (with respect to the reference run) for the freshwater source experiment. Negative (positive) anomalies denote anomalous (anti-)clockwise circulation. . . . . . . . . 47

14 Anomalous NADW outflow across $30^{\circ} \mathrm{S}$ set out against the difference in averaged pressure (anomalous with respect to reference run) between the Atlantic Ocean $\left(\pi_{A t l}\right)$ and the Southern Ocean $\left(\pi_{S O}\right)$, at $2000 \mathrm{~m}$ (solid line) and $150 \mathrm{~m}$ (dashed line) depth. Atlantic average is taken between $30^{\circ} \mathrm{S}$ to $75^{\circ} \mathrm{N}$, whereas the average pressure in the Southern Ocean is calculated in the circumpolar strip south of $30^{\circ} \mathrm{S}$. In general, the pressure differences between the Atlantic and the Southern Ocean (positive at depth, negative at shallower levels) decrease, in association with a reduced exchange. The wiggles at larger values of the outflow anomaly are related to the oscillations in the Southern Ocean. . . . . . . 48

15 Same as Fig. 12, but now for the experiment where a heat and salt source are switched on in the South Atlantic in year 1. . . . . . . . . . . . 49 
16 Density anomaly (in $10^{-3} \mathrm{~kg} \mathrm{~m}^{-3}$ ), zonally averaged over the Atlantic and over the upper $1500 \mathrm{~m}$, as function of time (vertical axis, in years) and latitude. The upper panel concerns the freshwater source experiment, showing that the maximum anomaly develops in the source area, and decreases northward. The lower panel concerns the heat and salt source experiment, where the density anomaly increases northward. . . . . . . 50 


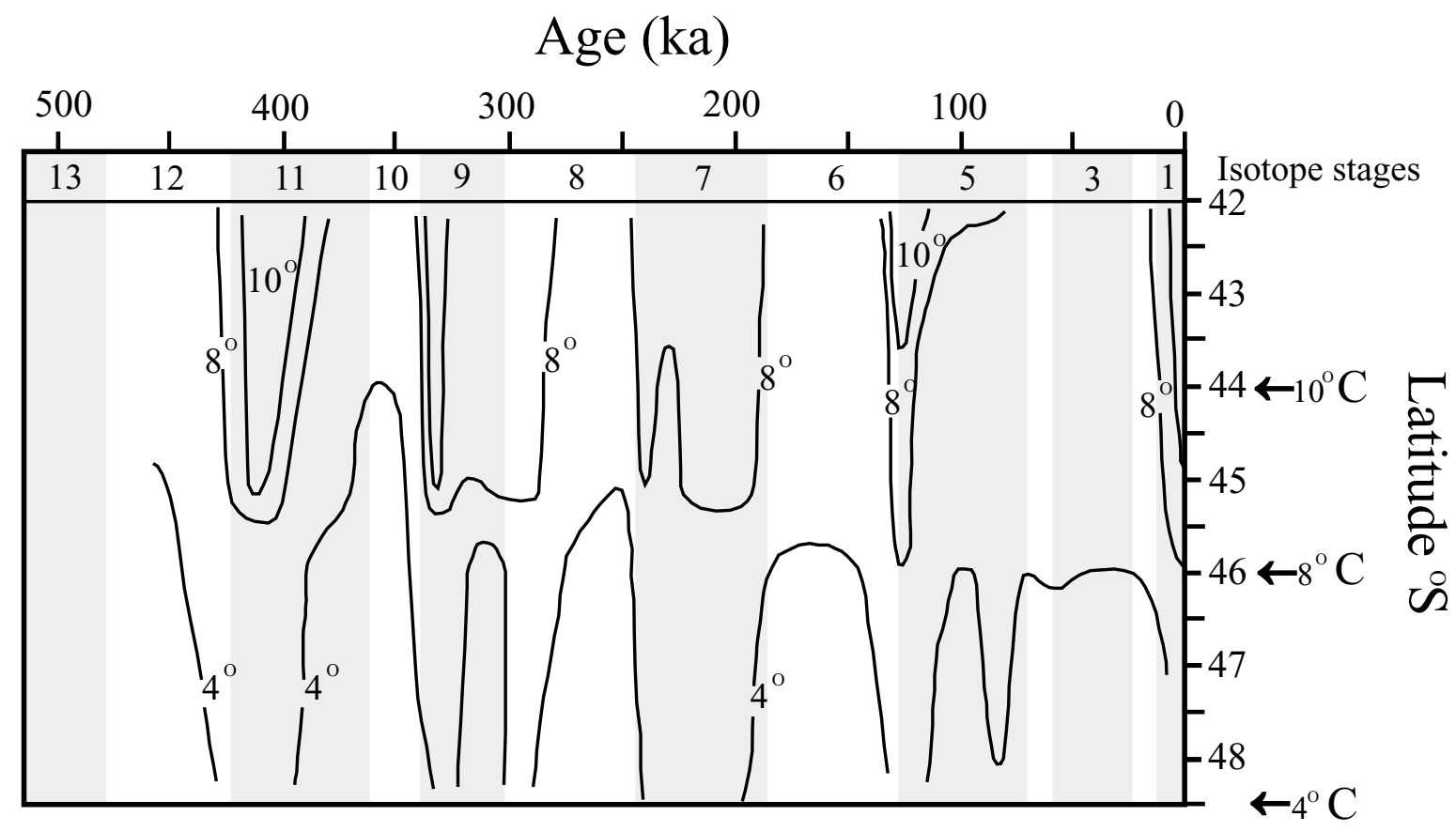

Figure 1 


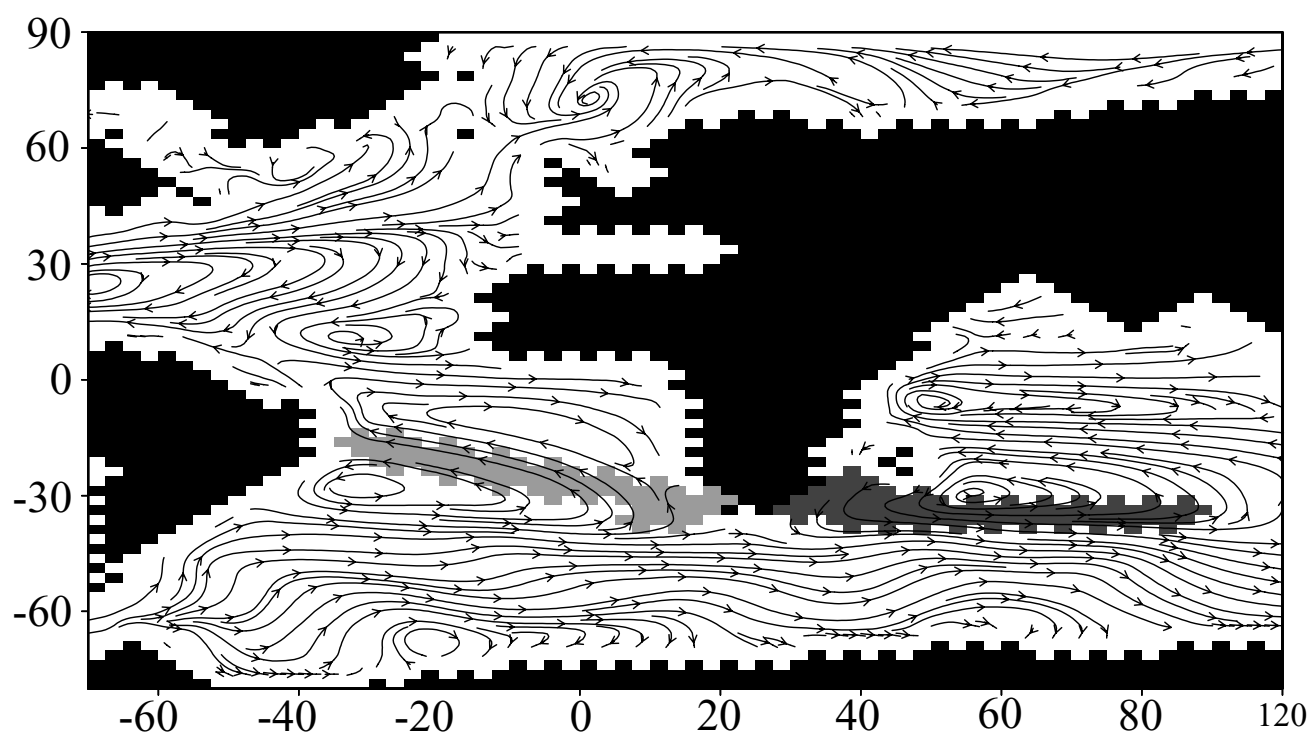

Figure 2 


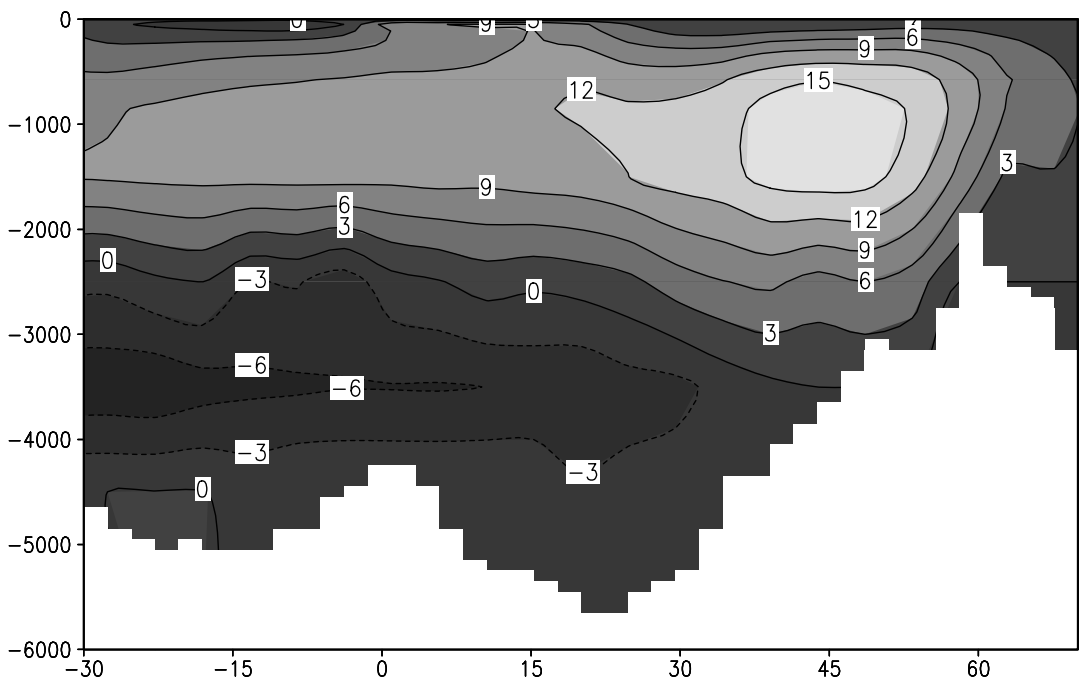

Figure 3 


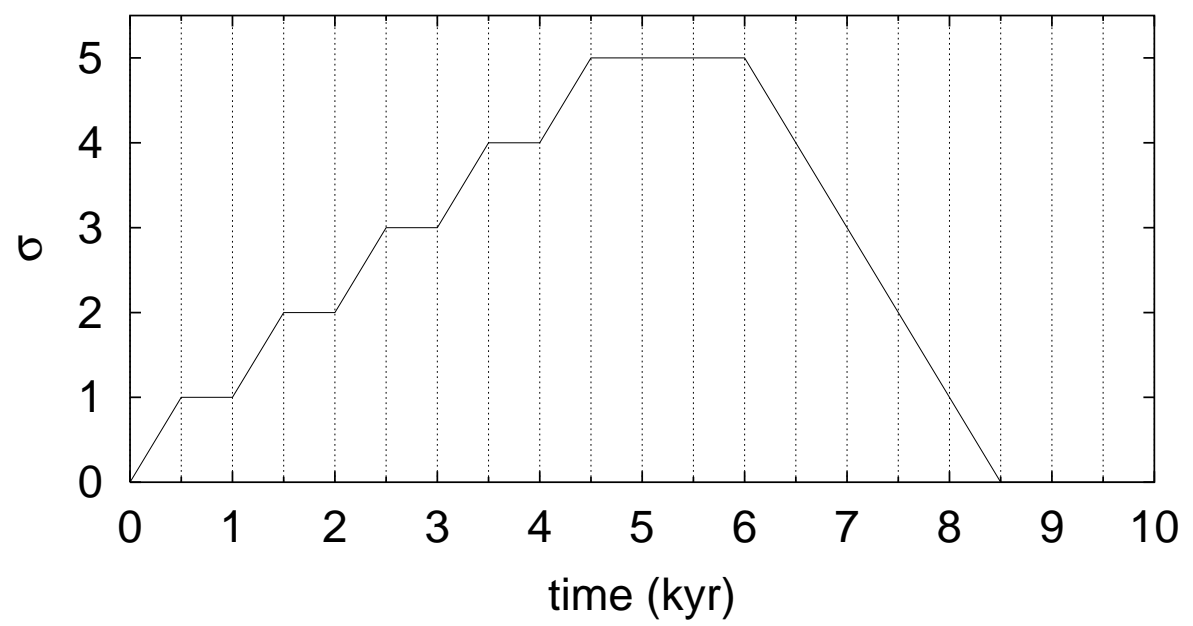

Figure 4 
a)

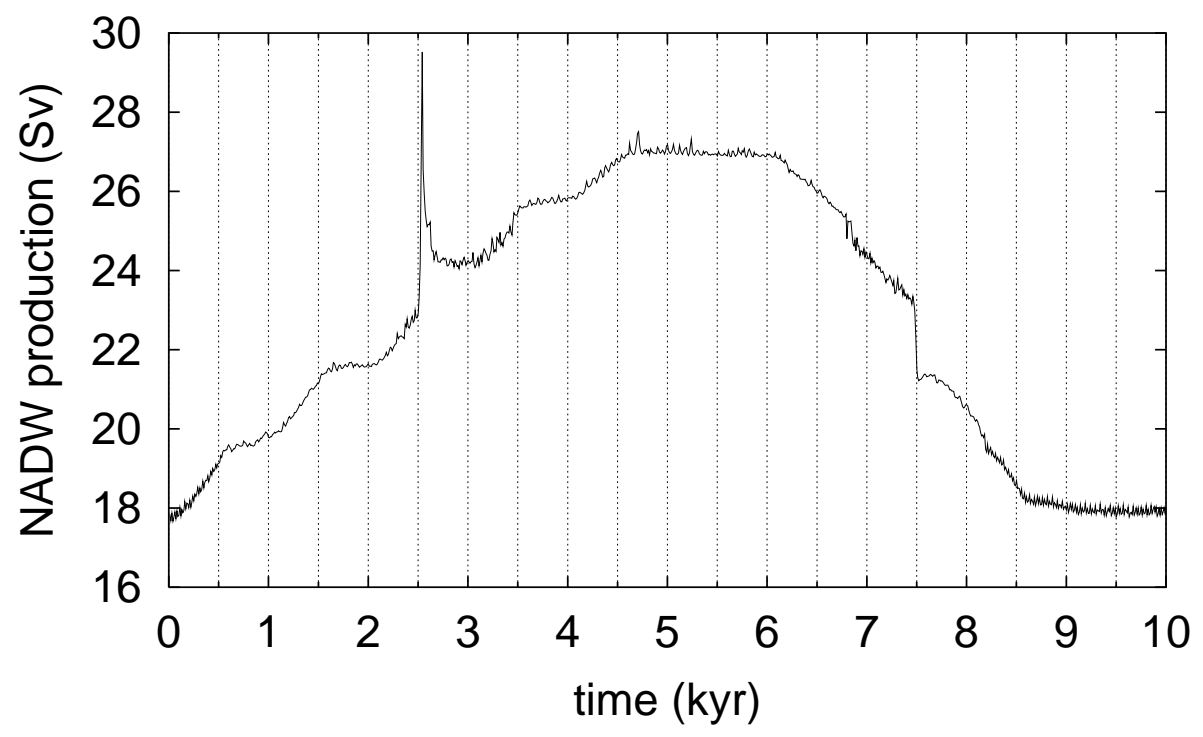

b)

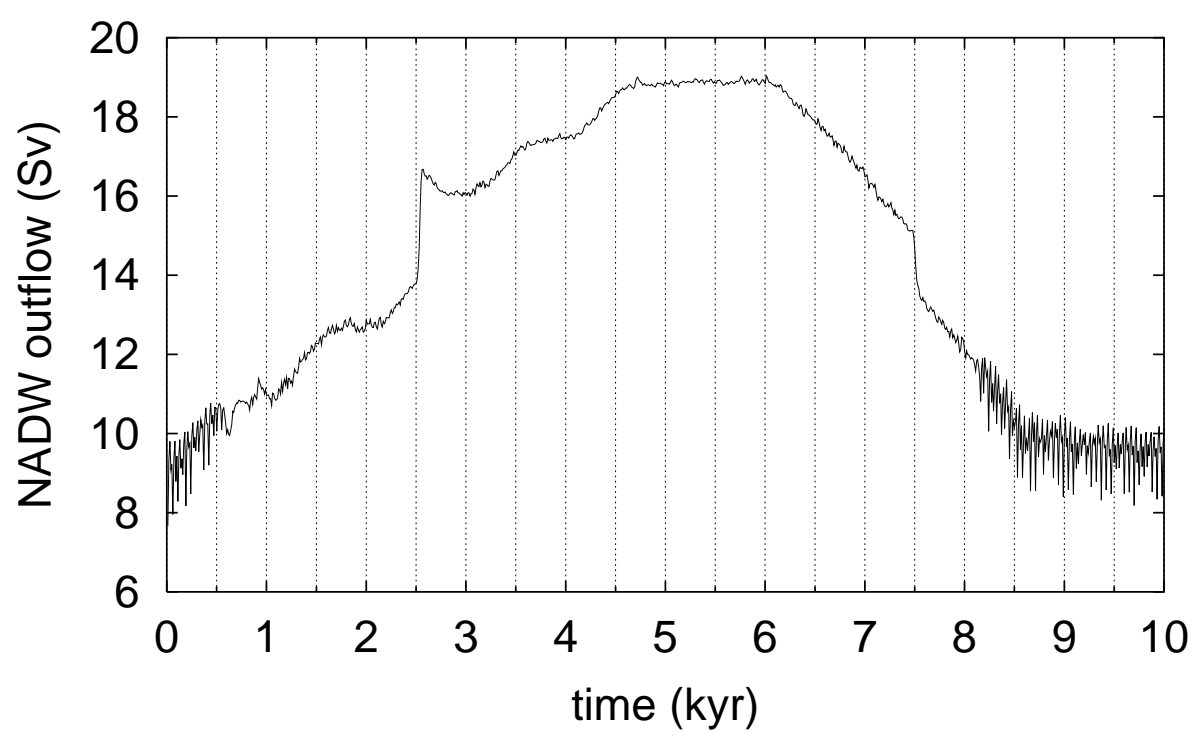

Figure 5 


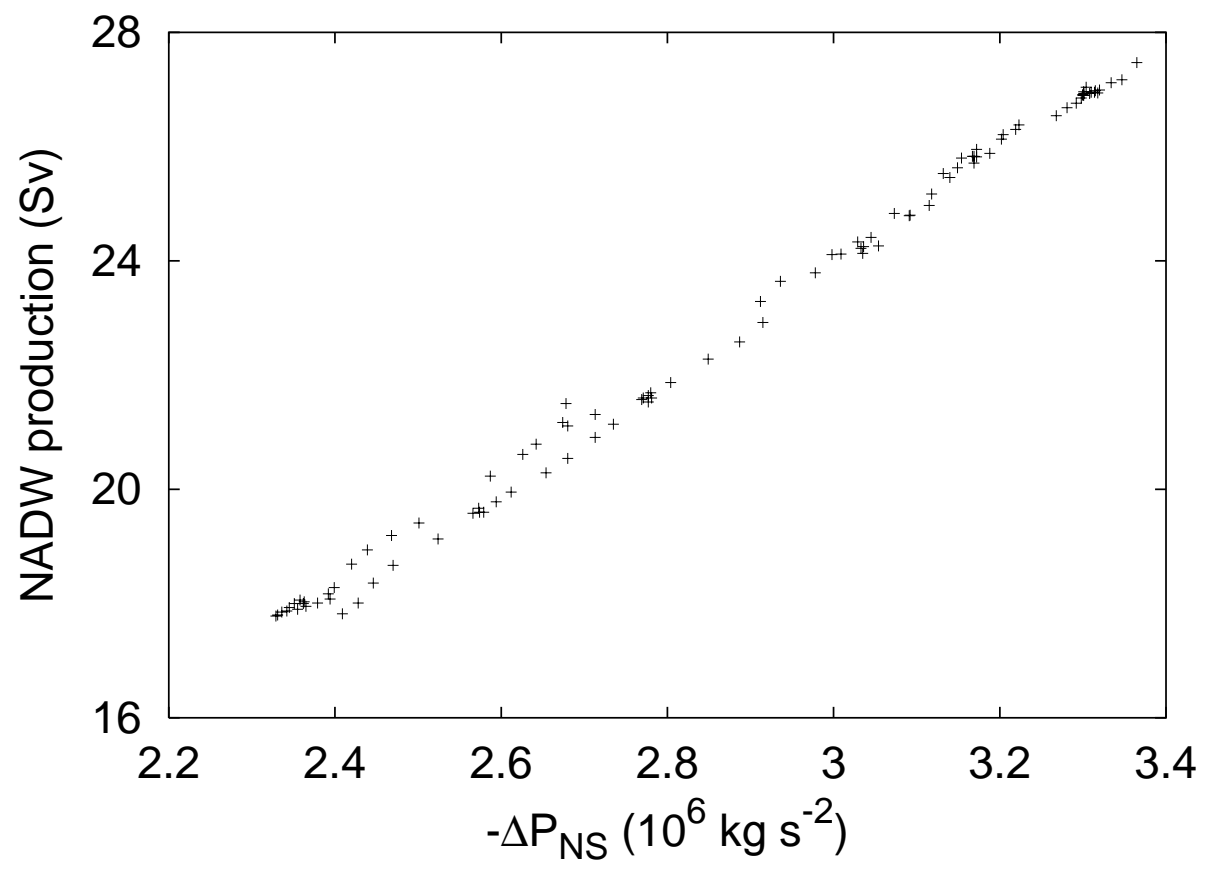

Figure 6 


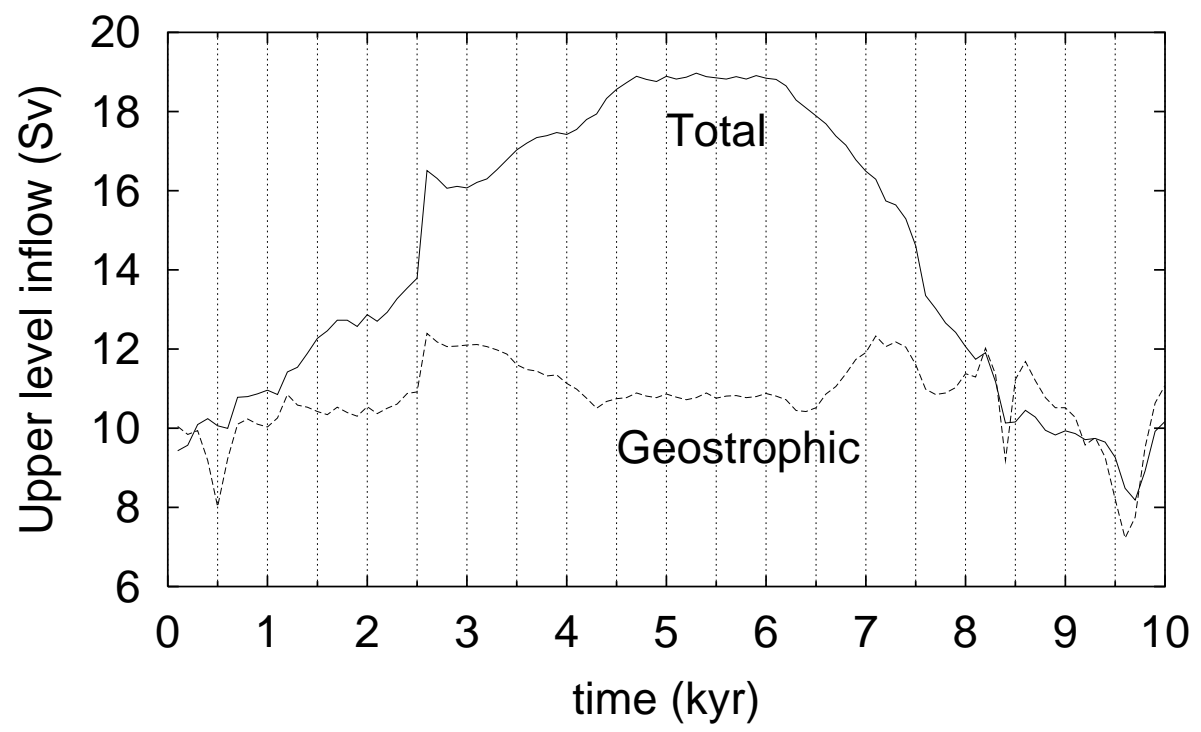

Figure 7 

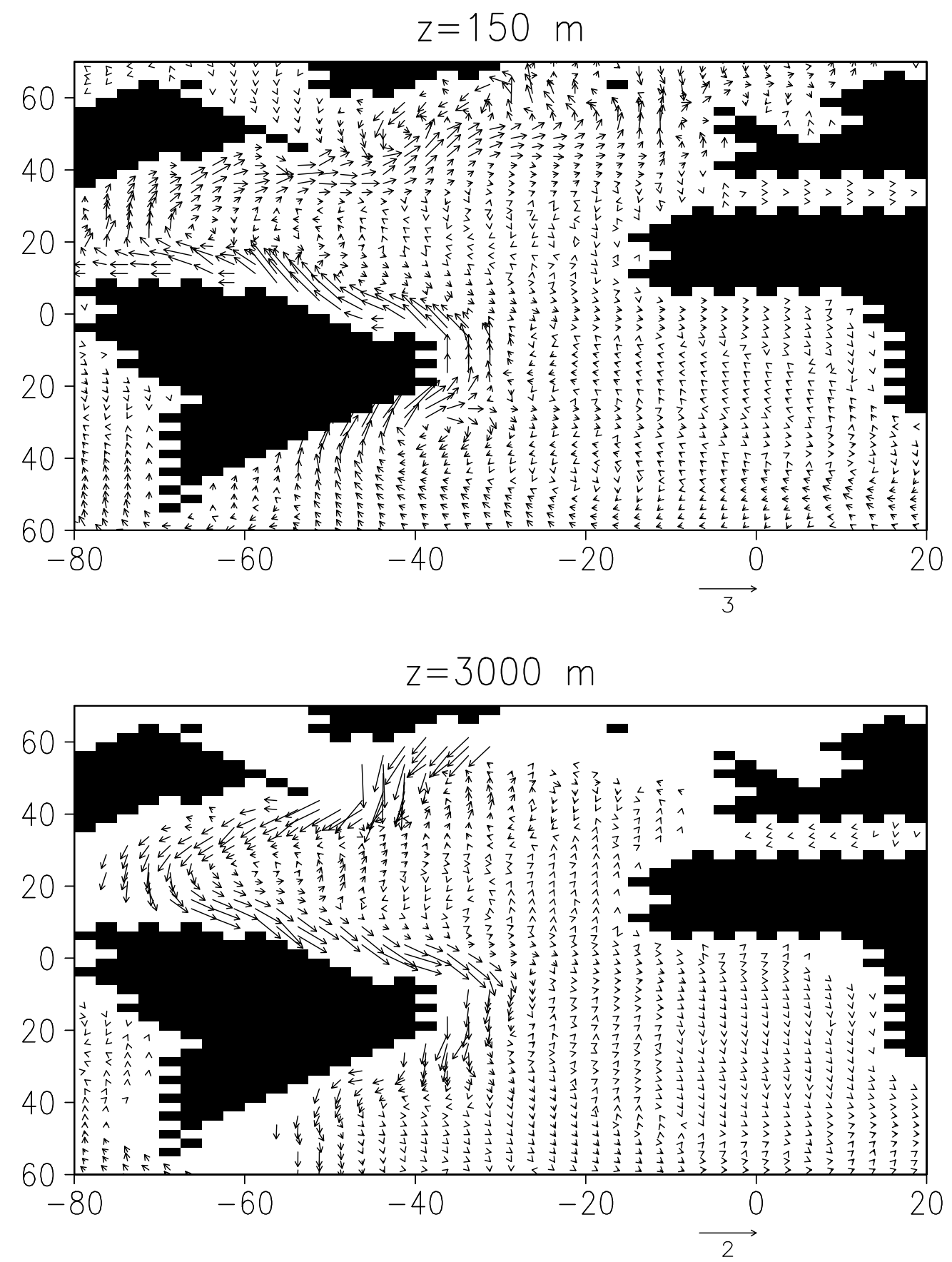

Figure 8 


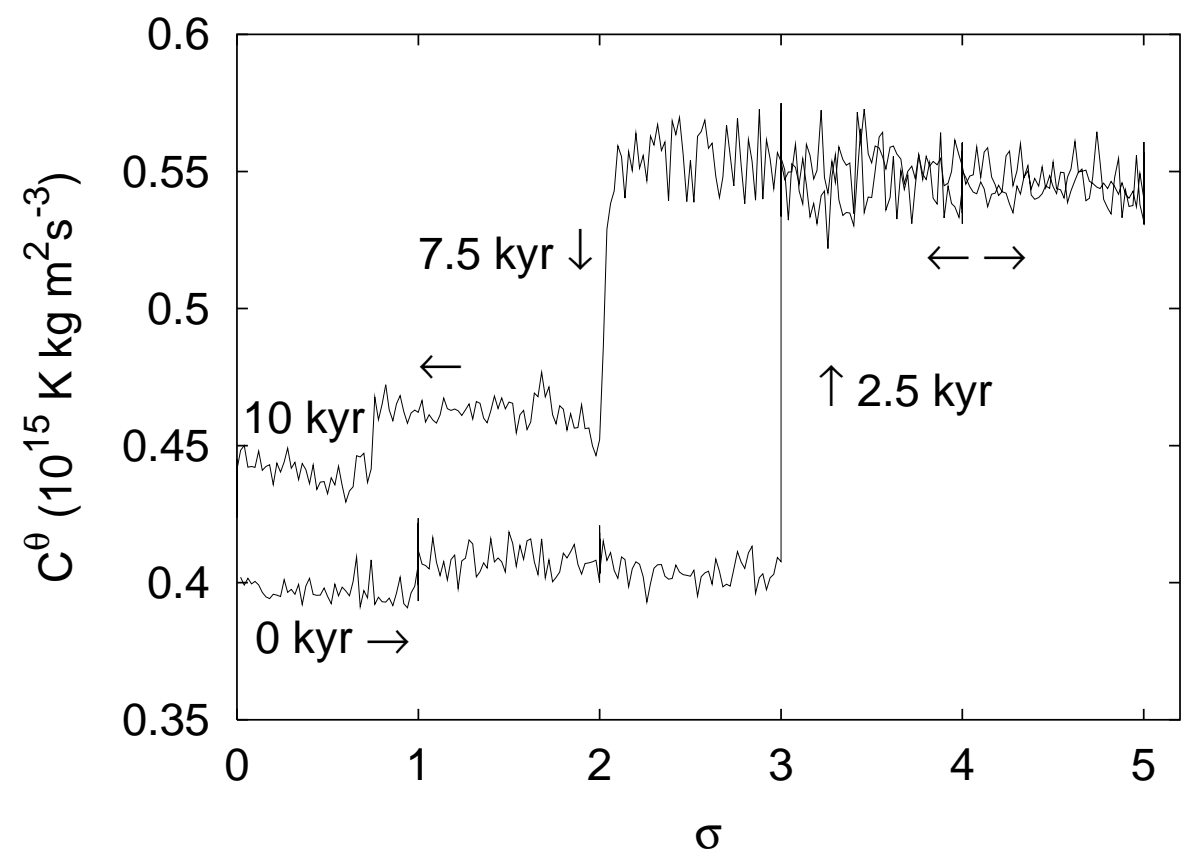

Figure 9 

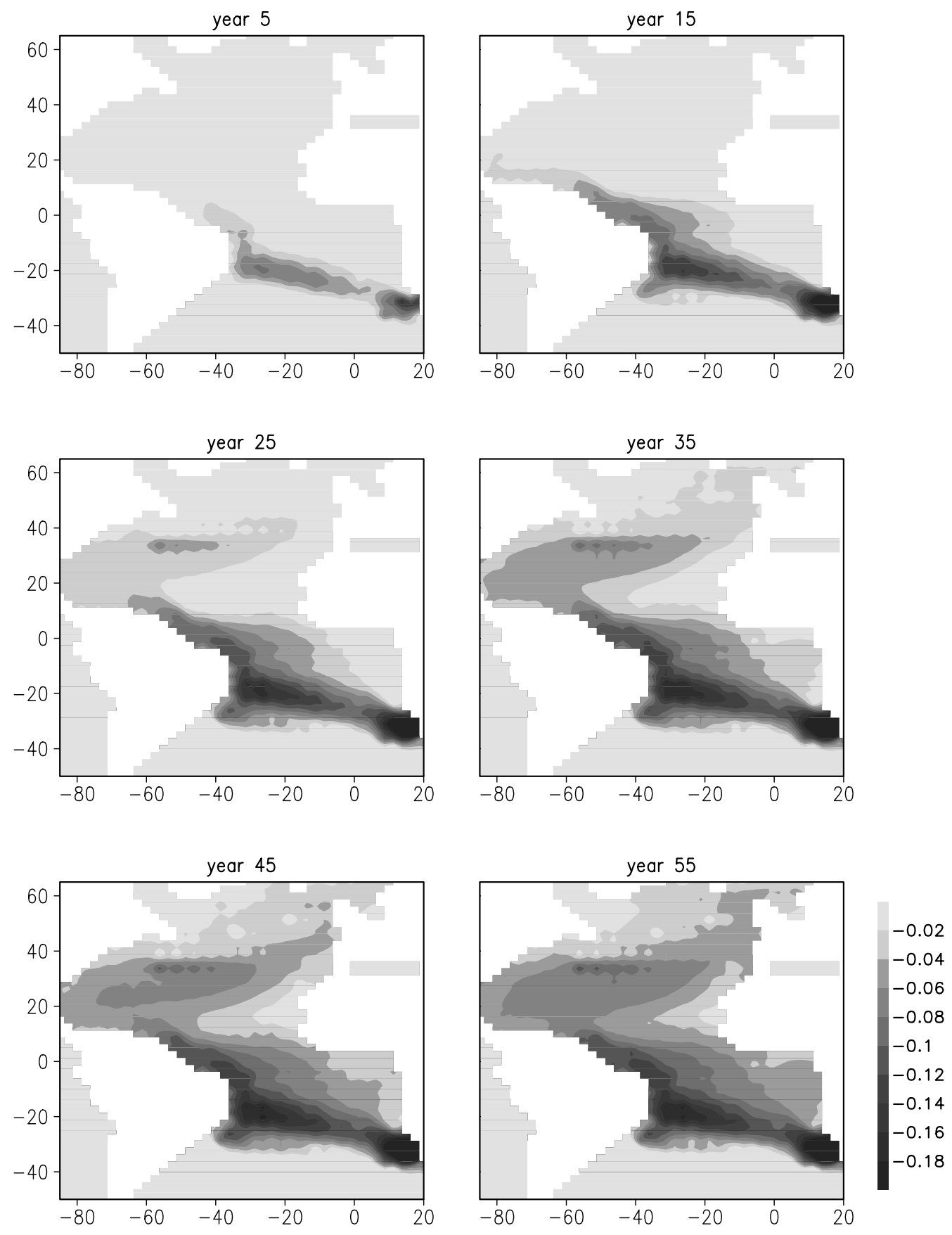

Figure 10 

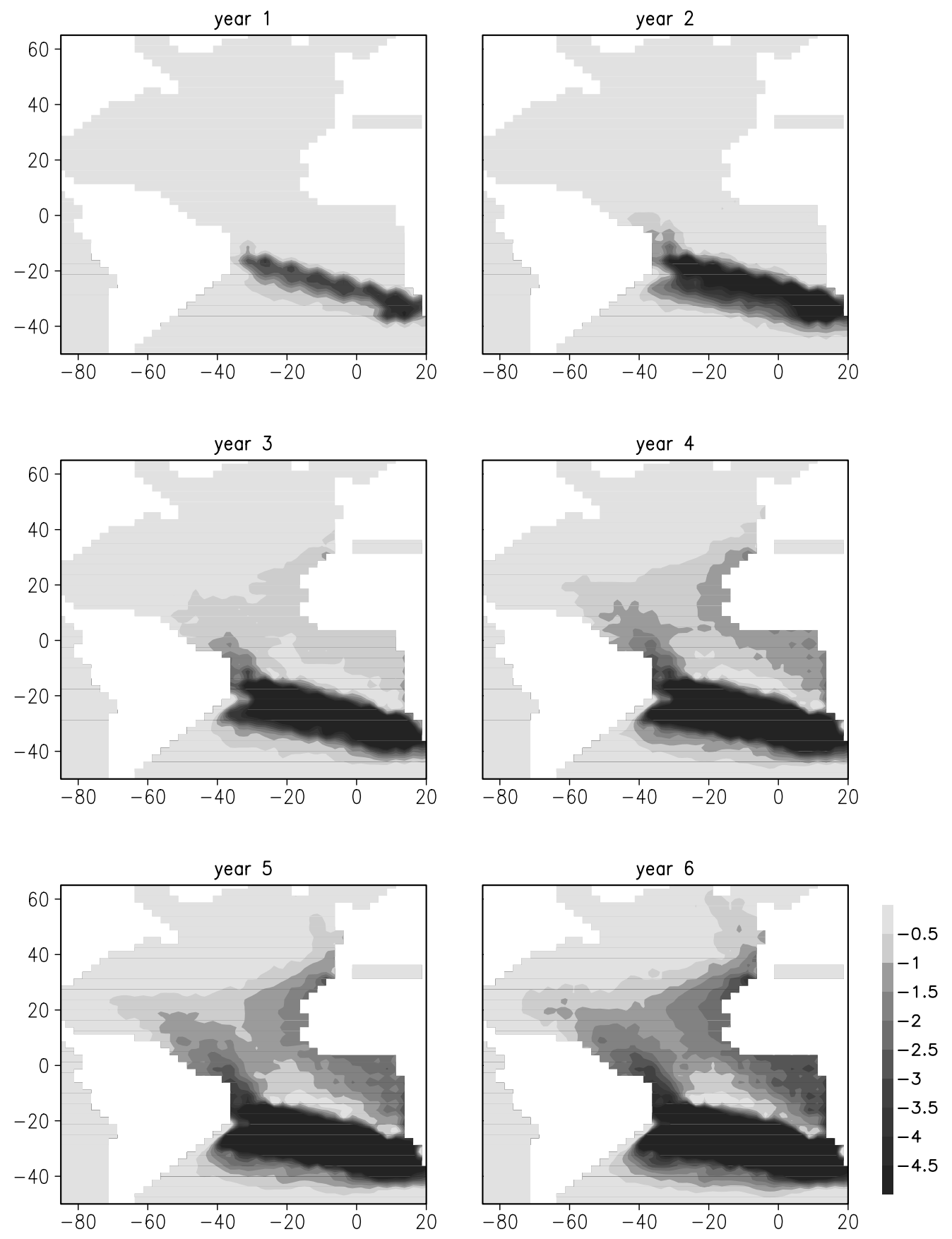

Figure 11 
a)

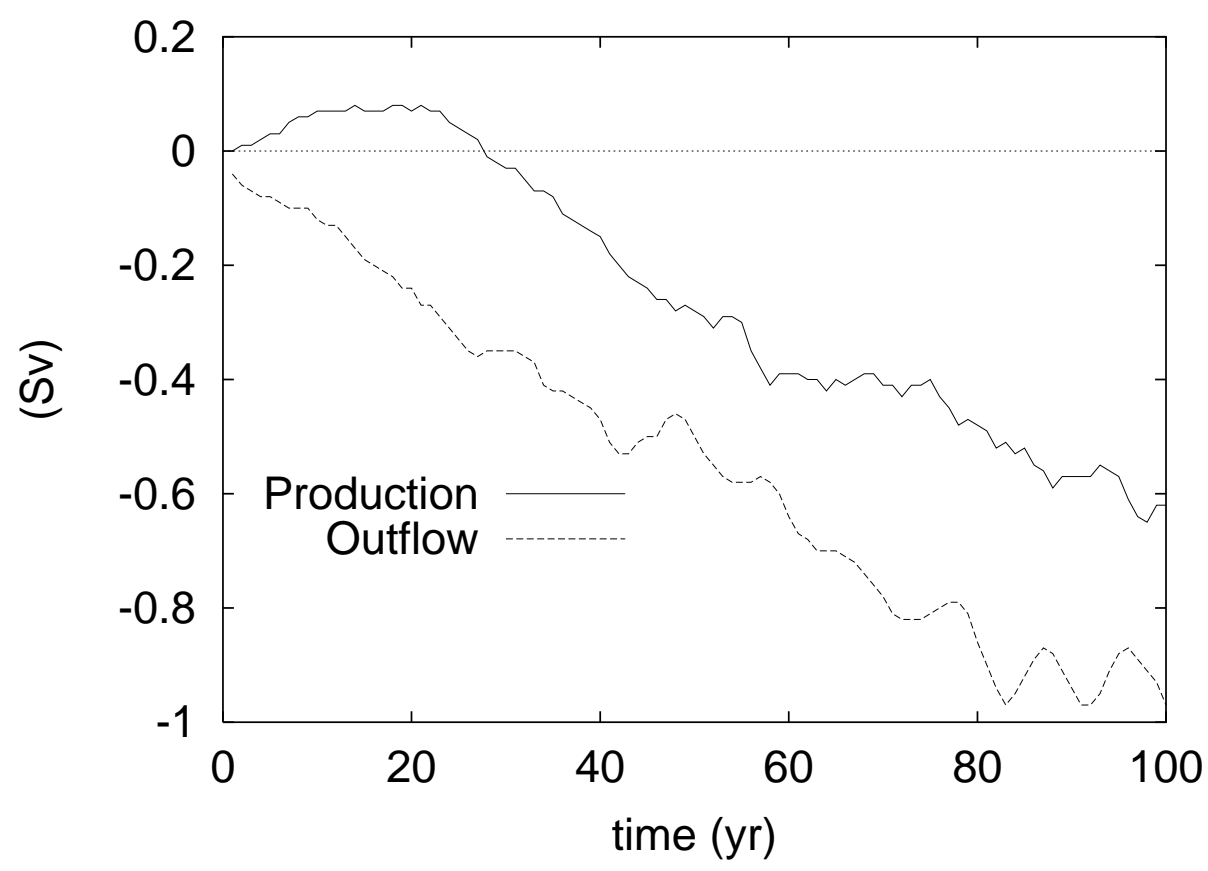

b)

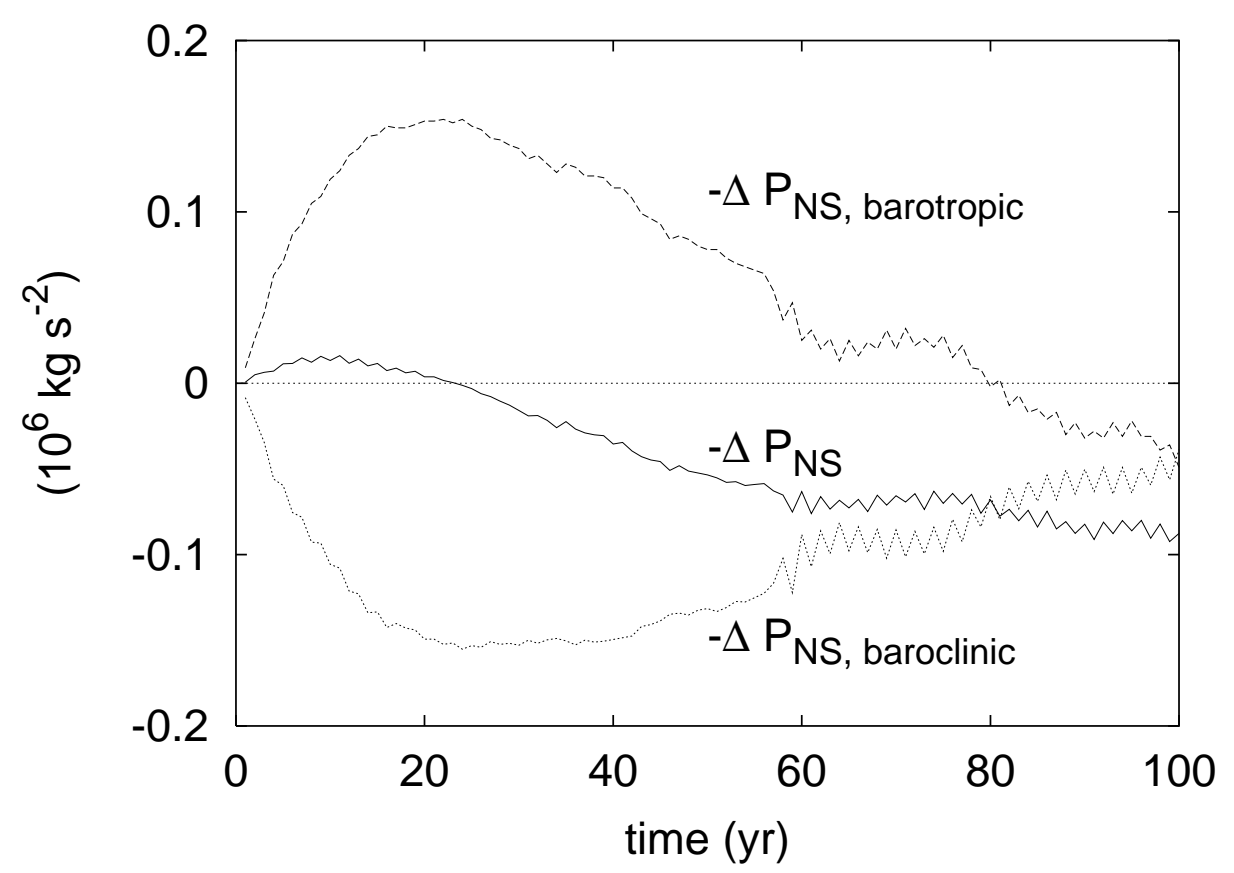

Figure 12 

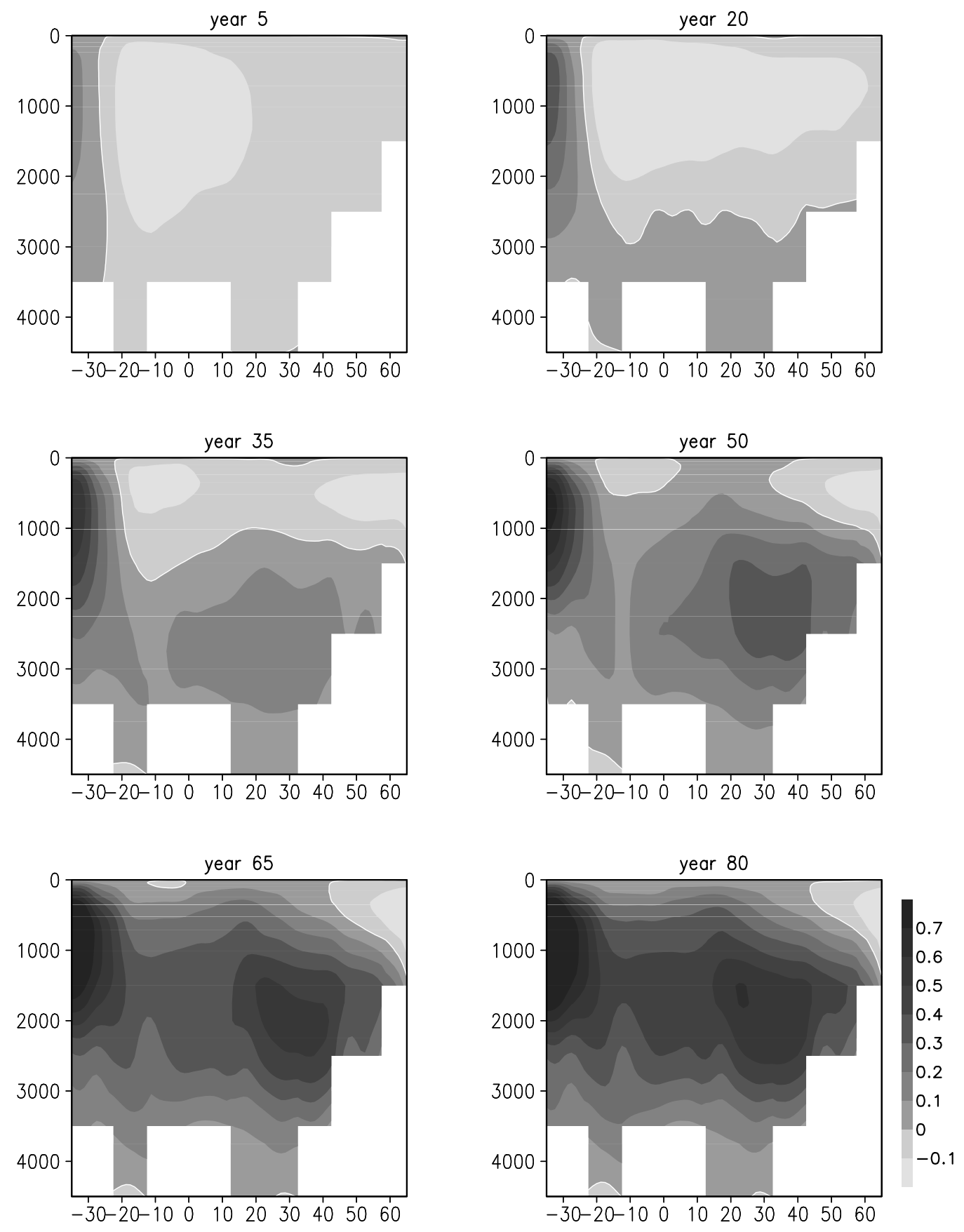

Figure 13 


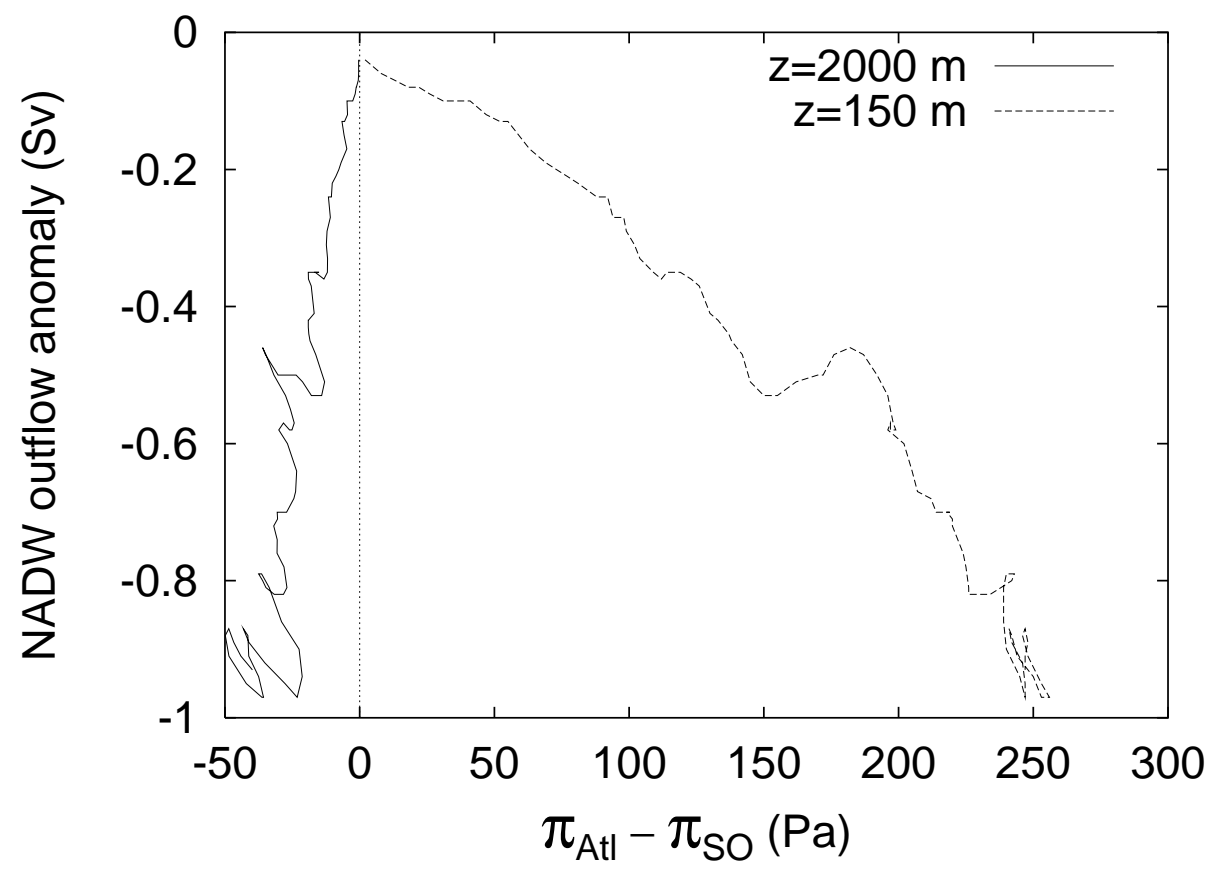

Figure 14 
a)

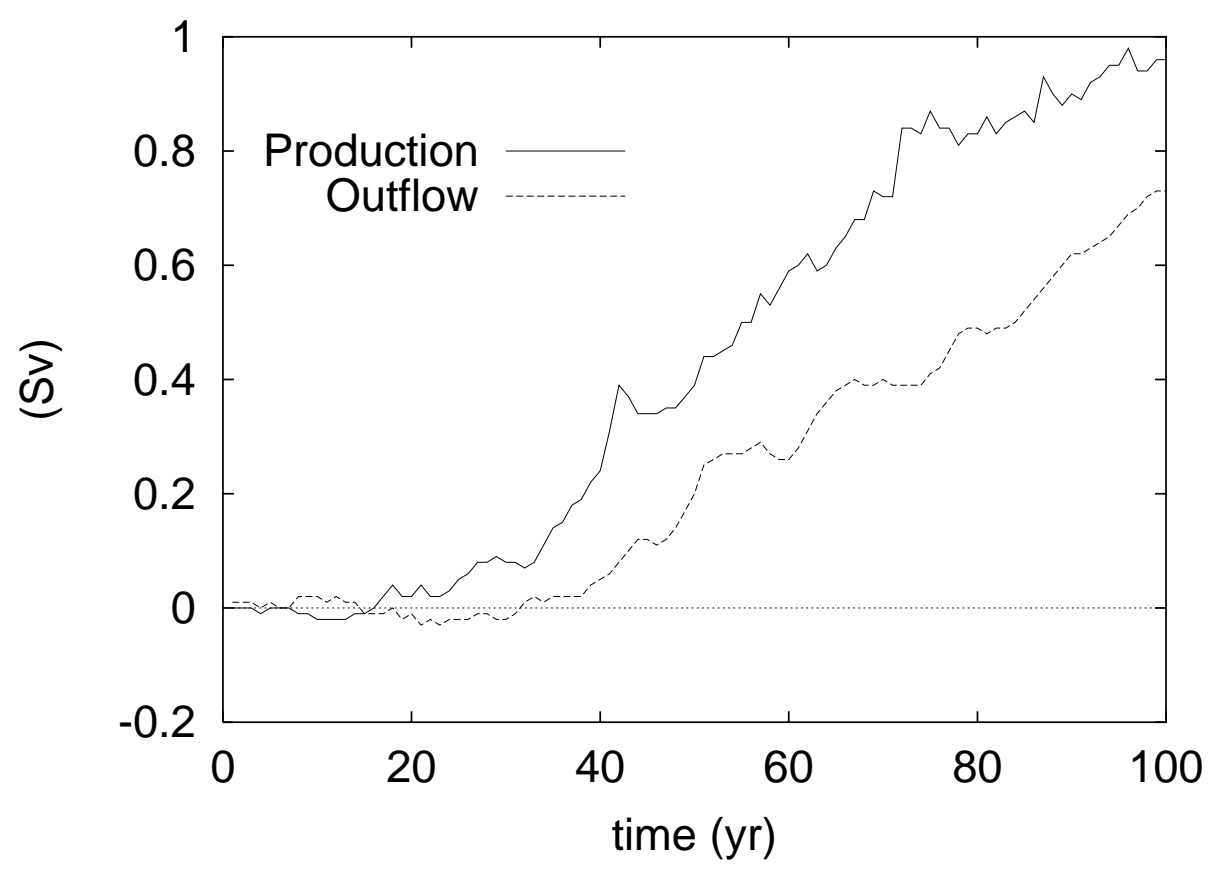

b)

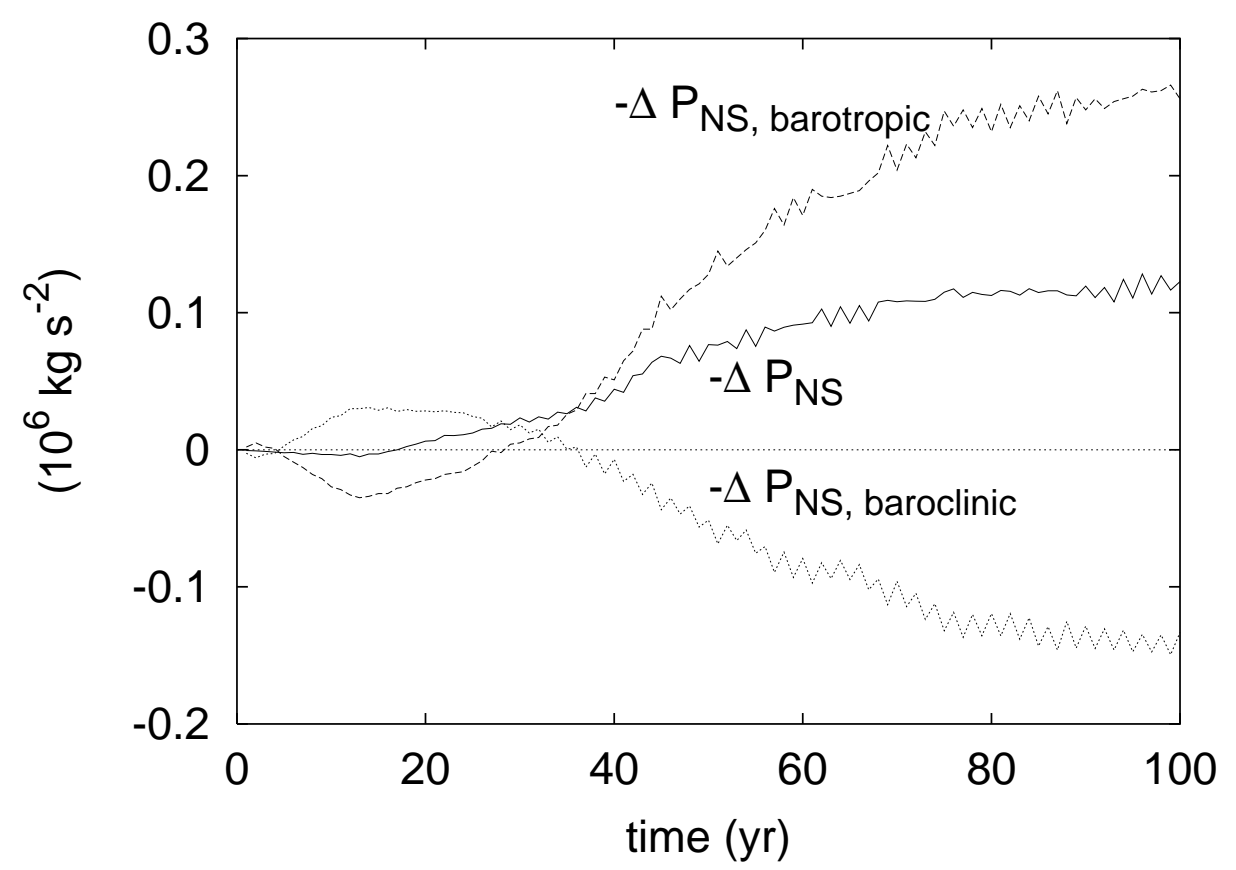

Figure 15 

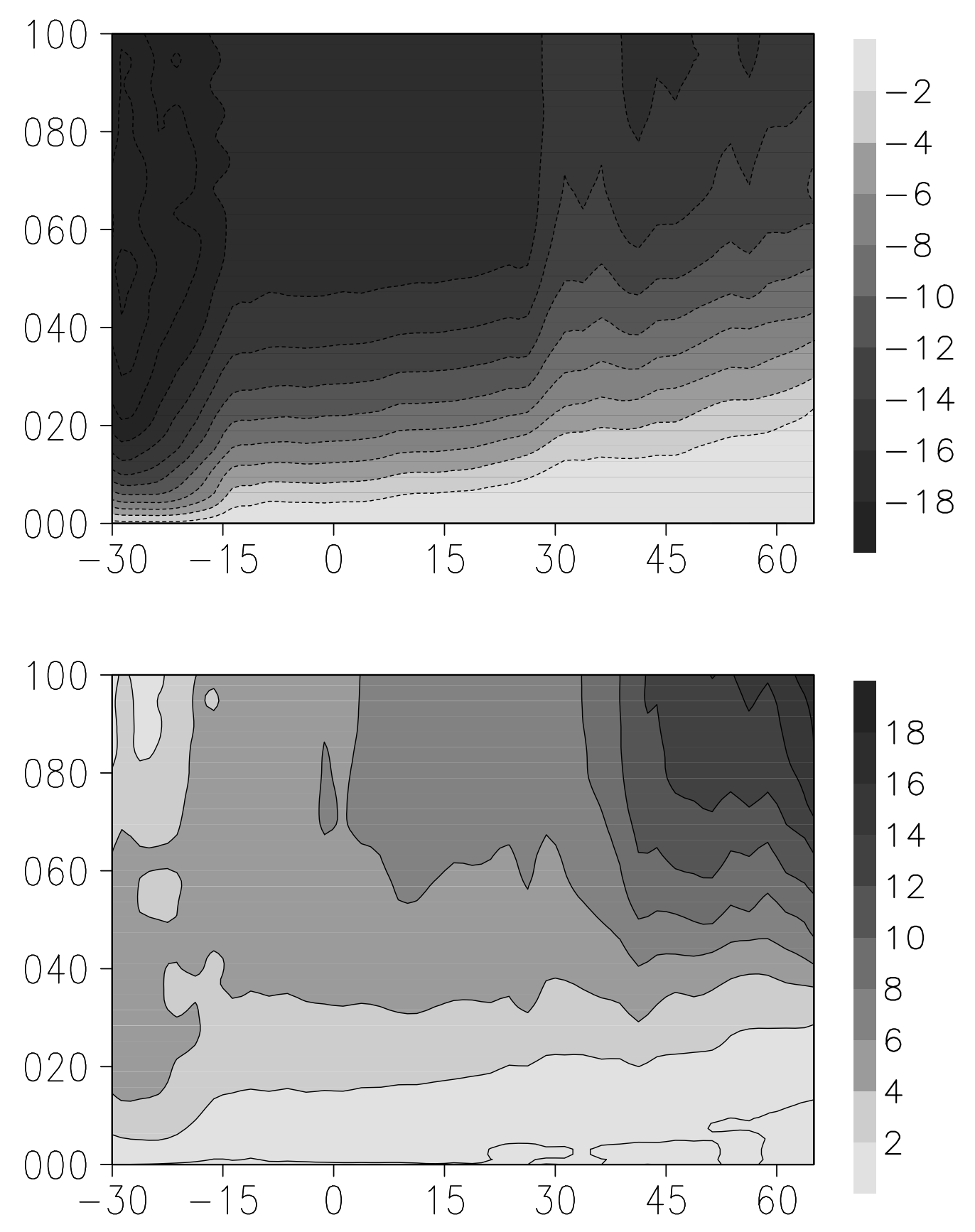

Figure 16 